\title{
Flow Injection Systems for Elemental Soil Analysis Determinations
}

\author{
Alexandra M. R. Ferreira, ${ }^{2}$ António O. S. S. Rangel,, and \\ José L. F. C. Lima \\ ${ }^{a}$ Escola Superior de Biotecnologia, Universidade Católica Portuguesa, Rua Dr. \\ António Bernardino de Almeida, 4200 Porto, Portugal \\ ${ }^{\mathrm{b}}$ CEQUP/Departamento de Química-Física, Faculdade de Farmácia, Rua \\ Aníbal Cunha 164, 4050 Porto, Portugal
}

\begin{abstract}
Flow injection analysis (FIA) is becoming an important automated procedure for the elemental analysis of agricultural and environmental samples. This paper reviews the application of the FIA technique for soil elemental analysis determinations, giving short descriptions of the required flow manifolds by highlighting some of their most important features.
\end{abstract}

\section{INTRODUCTION}

The control of the chemical composition of soil is of vital importance to both the agricultural and environmental sectors. It is, therefore, necessary to determine many analytical parameters for a large number of samples which is a demand that is becoming increasingly incompatible with the use of time consuming classical 
methods of analysis. Additionally, the legal limits concerning permissible levels of various elements are becoming even narrower, thus requiring the use of methodologies capable of determinations that can be made at very low concentration levels and with high precision. From these requirements, efficient automated analytical techniques that have high sensitivity and sample throughput characteristics have been developed.

The analysis of a soil involves five main procedural stages: sampling, preparation (drying, grinding, and conditioning), extraction or digestion procedure, preparation of the extracts/digests for measurement (involving dilution, concentration, separation, and the addition of reagents), and measurement of the analytical signal. The first three stages are difficult to automate mainly due to the need to handle solid samples. However, there would be a considerable economy of time, reagents, and technical personnel if the last two stages could be performed automatically. Two continuous flow methods, segmented flow analysis (SFA) and flow injection analysis (FIA), have been the developed to meet this need and they are commonly used for the analysis of soil extracts and digests for their elemental content.

Segmented flow analysis, proposed by Skeggs (1957), has been applied in different areas of analytical chemistry, such as food, clinical, and environmental sectors. It is based on the segmentation of the liquid flow with an air bubble, either air or nitrogen $\left(\mathrm{N}_{2}\right)$ gas, or even oil. These systems preserve the concept inherent to classical analysis by keeping the identity of the samples and performing measurements under conditions of equilibrium and homogenization. They are composed of sampling, propulsion, and bubble introduction devices, with intermediate devices capable of operations, such as dialysis, liquid-liquid extractions, and heating, followed by a bubble release system, and then a detection and data treatment device. These analyzers, commonly known as "AutoAnalyzers" which were first adapted to soil analysis in 1964 by Flannery and Steckel (Markus et al., 1985) for the determination of calcium (Ca) potassium (K), magnesium $(\mathrm{Mg})$, and phosphorus (P) in soil electrodialysates. However, other SFA systems for soil analysis have been reported since then for the determination of nitrogen (N) in its different forms (Keay and Menage, 1969; Selmer-Olsen, 1971; Li and Smith, 1984; Markus et al., 1985; Willis and Gentry, 1987, 1988; Tel and Heseltine, 1990a; Carlson et al., 1990; McLeod, 1992a, 1992b), sulphur (S) and sulphate $\left(\mathrm{SO}_{4}\right)$ (Lea and Wells, 1980), and chloride $(\mathrm{Cl})$ (Tel and Heseltine, 1990b). There are many other examples that could be presented. The main disadvantages of these SFA systems are their high cost and complex nature mainly due to the technical difficulties inherent in the segmentation as well as the need to perform the measurements under equilibrium and homogenization conditions. Normally, the useful analyte concentration range is two to three decades at best.

As an alternative to the SFA systems, FIA emerged in the 1970s (Ruzicka and Hansen, 1975), a methodology based on a non-segmented flow, which dramatically changed the existing automated concept method not requiring equilibrium 
conditions to be reached before detection. Its success is basically due to its simplicity, relatively low cost, versatility, high sampling rate, and low sample and reagent consumption. In addition, the analyte concentration range can be three to four orders of magnitude depending on the analyte concentration range. In the FIA system, the liquid analyte sample is injected into a moving, non-segmented continuous carrier stream of a suitable liquid. The injected sample forms a zone which is then transported towards a detector that continuously records either the absorbance, electrode potential, or other physical parameter with the passage of the analyte sample through the detector (Ruzicka and Hansen, 1975, 1988). Flow injection analysis combines three operational principles: sample injection, controlled dispersion of the injected sample zone, and reproducible timing of its movement from the injection point to the detector.

The interest that the FIA technique has generated in different fields of analytical chemistry is clearly seen by the large number of papers published in various international journals as well as the Journal of Flow Injection Analysis which is totally devoted to this methodology. Several books (Valcárcel and Luque de Castro, 1987; Ruzicka and Hansen, 1988; Burguera, 1989; Karlberg and Pacey, 1989; Fang, 1993) have also been published on the FIA technique. The simplicity and versatility of the manifolds and their ease of coupling to the detection devices make this analytical procedure suitable for its application for many different matrices in several areas of analytical chemistry, including agricultural (Appelqvist et al., 1986; Catalayud, 1985) and the environmental (Luque de Castro and Valcárcel, 1990). In fact, most of the early routine FIA systems, such as those proposed in Brazil and later in China, were employed for determining chemical species in water, and plant and soil sample extracts and/or digests (Karlberg and Pacey, 1989).

The relatively large number of papers reporting on FIA methods developed for soil analysis justifies the compilation of all this work, reviewing the important features of each analytical technique.

\section{FIA APPLICATIONS FOR SOIL ANALYSIS}

Flow injection manifolds which have been developed for the analysis of soil extracts and digests can be divided into five groups of chemical species, cationic, anionic, $\mathrm{N}$ compounds and $\mathrm{P}$ compounds, and elemental and molecular species. Within each group, we will present the analyte species in alphabetical order and then chronologically. Some of the characteristics of these systems are also given in a generalized form in Table 1 where all the species are listed alphabetically.

Ultraviolet/visible (UV/Vis) and atomic absorption spectrophotometry (AAS) are the most widely used detection systems (Figure 1), thereby employing existing analytical methodology and detection techniques already in use in manual analytical procedures. For easy adaptation of these detectors to the flow systems, 
TABLE 1. Flow injection system application to soil analysis.

\begin{tabular}{|c|c|c|c|c|c|c|}
\hline Analyte & Matrix & FIA mode & Method/Detection & $\begin{array}{c}\mathbf{R S D}^{(\mathbf{a})} \\
(\%)\end{array}$ & $\begin{array}{c}\mathrm{SR}^{(\mathrm{b})} \\
\left(\mathrm{h}^{-1}\right)\end{array}$ & References \\
\hline Aluminium & $\begin{array}{l}\mathrm{KCl} \text { soil extracts } \\
\mathrm{KCl} \text { soil extracts } \\
\text { Soil extracts }\end{array}$ & $\begin{array}{l}\text { Merging zones } \\
\text { Simple/Three-line } \\
\text { Simple/Three-line }\end{array}$ & $\begin{array}{c}\text { UV } / \text { is } \\
\text { Amperometry } \\
\text { UV } N \text { is }\end{array}$ & $\begin{array}{l}<1 \\
4.3\end{array}$ & $\begin{array}{c}120 \\
60\end{array}$ & $\begin{array}{c}\text { Reis et al., } 1979 \\
\text { Downard et al., } 1992 \\
\text { Hawke and Powell, } 1994\end{array}$ \\
\hline Antimony & Soil extracts & Simple/Two-line & Hydride generat.-AAS & $0.4-0.9$ & - & Wang and Wang, 1992 \\
\hline Arsenic & Soil extracts & Simple/Two-line & Hydride generat.-AAS & $0.4-0.9$ & - & Wang and Wang, 1992 \\
\hline Bismuth & Soil extracts & Simple/Two-line & Hydride generat.-AAS & $0.4-0.9$ & - & Wang and Wang, 1992 \\
\hline Boron & $\begin{array}{c}\text { Soil extracts } \\
\mathrm{H}_{2} \mathrm{O} \text { soil extracts } \\
\mathrm{H}_{2} \mathrm{O} \text { soil extracts } \\
\mathrm{CaCl}_{2} \text { soil extracts }\end{array}$ & $\begin{array}{c}\text { Simple/Three-line } \\
\text { Simple/Single-line } \\
\text { Reversed FIA system } \\
\text { Time-based injection/Four-line }\end{array}$ & $\begin{array}{l}\text { UV/Vis } \\
\text { UV/Vis } \\
\text { UV/Vis } \\
\text { UV/Vis }\end{array}$ & $\begin{array}{c}1.0 \\
0.9 \\
1.1 \\
<1.2\end{array}$ & $\begin{array}{l}60 \\
70 \\
50 \\
200\end{array}$ & $\begin{array}{c}\text { Sun et al., } 1983 \\
\text { López-Garcia et al., } 1988 \\
\text { López-Garcia et al., } 1988 \\
\text { Carrero et al., } 1993\end{array}$ \\
\hline Bromide & Synthetic soils extracts & Simple/Two-line & Potentiometry & 1.6 & 80 & Van Staden, 1987 \\
\hline Cadmium & Soil digests & On-line sorbent extraction & AAS & - & - & Ma et al., 1994 \\
\hline
\end{tabular}




\begin{tabular}{|c|c|c|c|c|c|c|}
\hline \multirow[t]{5}{*}{ Calcium } & $\mathrm{KCl}$ soil extracts & Zone sampling/Merging zones & UV/Vis & $<1.0$ & 180 & Jacintho et al., 1981 \\
\hline & Soil extracts & Merging zones & AAS & 1.0 & 540 & Zhang et al., 1984 \\
\hline & Soil extracts & Simple/Two-line & AAS & $<3.0$ & $60-120$ & Krug et al., 1987 \\
\hline & $\mathrm{H}_{2} \mathrm{O}$ soil extracts & Flow splitting & AAS & $<2$ & 120 & Ferreira et al., 1995a \\
\hline & $\mathrm{NH}_{4} \mathrm{Ac}$ soil extracts & Dialysis & AAS & $<4$ & 60 & Ferreira et al., 1995a \\
\hline $\mathrm{Ca} / \mathrm{L} / \mathrm{K} / \mathrm{Na}$ & $\mathrm{NH}_{4} \mathrm{Ac}$ soil extracts & MulticomponentTwo-line & Grad. scan./FS & $2.5-4.6$ & - & Fang et al., 1985 \\
\hline $\mathrm{Ca} / \mathrm{K} / \mathrm{C} /$ Nitrate & $\mathrm{NaAc}$ soil extracts & Multicomponent/Single-line & Potentiometry & $0.3-3.2$ & - & Cardwell et al., 1988 \\
\hline $\mathrm{Ca} / \mathrm{K}$ & $\mathrm{NH}_{4} \mathrm{Ac}$ soil extracts & Multicomponent/Dialysis & AAS/FES & $<3$ & 80 & Ferreira et al., 1995b \\
\hline $\mathrm{Ca} / \mathrm{Mg}$ & $\mathrm{NH}_{4} \mathrm{Ac}$ soil extracts & Multicomponent/Dialysis & AAS/AAS & $<3$ & 100 & Ferreira et al., 1995b \\
\hline $\mathrm{Ca} / \mathrm{Mg}$ & $\mathrm{KCl}$ soil extracts & Multicomponent/Multi-site detection & UV/Vis & $<2.0$ & 160 & Nogueira et al., 1996 \\
\hline Chromium & Soil extracts & Simple/Two-line & UV/Vis & 1.3 & 70 & Jorgensen and Regitano, 1980 \\
\hline \multirow[t]{2}{*}{ Chloride } & $\mathrm{H}_{2} \mathrm{O}$ soil extracts & Microconduits/Two-line & Potentiometry & - & $120-200$ & Hongbo and Junyan, 1991 \\
\hline & $\mathrm{H}_{2} \mathrm{O}$ soil extracts & Pseudo-titration & Potentiometry & $<4.8$ & $60-160$ & Ferreira et al., 1996a \\
\hline \multirow[t]{2}{*}{ Copper } & Soil extracts & Simple/Single-line & AAS & 1.0 & 514 & Zhang et al., 1984 \\
\hline & Soil digests & On-line sorbent extraction & AAS & - & - & Ma et al., 1994 \\
\hline Iron & $\mathrm{HCl}$ soil extracts & Simple/Single-line & UV/Vis & - & 200 & Cui and Fang, 1984 \\
\hline
\end{tabular}

(continued) 
TABLE 1. Continued.

\begin{tabular}{|c|c|c|c|c|c|c|}
\hline Iron & Soil extracts & Simple/Single-line & AAS & 1.0 & 514 & Zhang et al., 1984 \\
\hline & Soil extracts & Simple/Three-line & UV/Vis & $<1.7$ & 60 & Ferreira et al., 1996b \\
\hline & Soil extracts & Simple/One-line & AAs & $<4.8$ & 300 & Ferreira et al., 1996d \\
\hline Lead & Soil digests & On-line sorbent extraction & AAS & - & - & Ma et al., 1994 \\
\hline Magnesium & Soil extracts & Merging zones & AAS & 1.0 & 514 & Zhang et al., 1984 \\
\hline & Soil extracts & Simple/Two-line & AAS & $<3.0$ & $60-120$ & Krug et al., 1987 \\
\hline & $\mathrm{H}_{2} \mathrm{O}$ soil extracts & Flow splitting & AAS & $<2$ & 150 & Ferreira et al., 1995a \\
\hline & $\mathrm{NH}_{4} \mathrm{Ac}$ soil extracts & Dialysis & AAS & $<3$ & 60 & Ferreira et al., 1995a \\
\hline $\mathrm{Mg} / \mathrm{Na}$ & $\mathrm{NH}_{4} \mathrm{Ac}$ soil extracts & Multicomponent/Dialysis & AAS/FES & $<3$ & 100 & Ferreira et al., 1995b \\
\hline Manganese & Soil extracts & Simple/Single-line & AAS & 1.0 & 514 & Zhang et al., 1984 \\
\hline & Soil extracts & Simple/Two-line & UV/Vis & $<1$ & 60 & Mesquita et al., 1989 \\
\hline Mercury & Soil extracts & Gas-diffusion & Cold vapour-AAS & 1 & 200 & Zhang et al., 1987 \\
\hline & Soil digests & Gas-diffusion & Fluorescence & 2 & 40 & Narinesingh et al., 1994 \\
\hline Molybdenum & Soil extracts & Ion exchange column & ICP-AES & 5.3 & 12 & Guo et al., 1993 \\
\hline Nitrogen & & & & & & \\
\hline Ammonia-N & Soil digests & Simple/Three-line & Turbidimetry-UV/Vis & 1.5 & 120 & Krug et al., 1979 \\
\hline
\end{tabular}




\begin{tabular}{|c|c|c|c|c|c|c|}
\hline \multirow[t]{3}{*}{ Ammonium-N } & Soil extracts & Gas-diffusion & UV/Vis & $0.3-0.5$ & 6 & Shirato et al., 1989 \\
\hline & $\mathrm{KCl}$ soil extracts & Reversed FIA system & UV/Vis & $<1.34$ & 40 & Raigon et a., 1992 \\
\hline & $\mathrm{KCl}$ soil extracts & Simple/Four-line & UV/Vis & - & 60 & Alves et al., 1993 \\
\hline \multirow[t]{5}{*}{ Nitrate-N } & Soil extracts & SimplerTwo-line & Potentiometry & 0.8 & 120 & Ruzicka et al., 1977 \\
\hline & Saturated soil extracts & Simple/Single-line & Potentiometry & - & 20 & Schalscha et al., 1981 \\
\hline & Soil extracts & $\mathrm{Cu}-\mathrm{Cd}$ reduction column & UV/Vis & $0.3-0.5$ & 6 & Shirato et al., 1989 \\
\hline & Soil extracts & Double injection/Four-line & Potentiometry & - & 180 & Liu et al., 1992 \\
\hline & $\mathrm{KCl}$ soil extracts & Cd-reduction column & UVrvis & $<0.55$ & 40 & Raígon et al., 1992 \\
\hline Nitrite-N & Soil extracts & Sandwich technique & $\mathrm{UV} / \mathrm{V}$ is & $0.3-0.5$ & 6 & Shirato et al., 1989 \\
\hline \multirow[t]{4}{*}{ Total-N } & Soil digests & Simple/Four-line & UV/Vis & 3.5 & 120 & Sun et al., 1981 \\
\hline & Soil digests & Gas-diffusion & UVrVis & 1.1 & - & Sun et al., 1986 \\
\hline & Soil digests & Gas-diffusion & UV/Vis & $2.1-5.4$ & - & Nakajima and Yanagihara, 1993 \\
\hline & Soil digests & Gas-diffusion & Potentiometry & $<5$ & 80 & Ferreira et al., 1996c \\
\hline Urea-N & $\mathrm{KCl}$ soil extracts & Simple/Four-line & UV/Vis & - & 60 & Sullivan and Havlin, 1991 \\
\hline Nitrate/Nitrite & Soil extracts & Multicomponent/Cd reduction column & UV/Vis & $0.7-1.0$ & 120 & $\mathrm{Xu}$ and Fang, 1983 \\
\hline Nitrate/Nitrite & Soil extracts & Multicomponent/Cd reduction column & $\mathrm{UV} / \mathrm{Vis}$ & - & 45 & Karlicek et al., 1988 \\
\hline \multirow[t]{2}{*}{$\mathrm{pH}$} & $\mathrm{CaCl}_{2}$ soil extracts & Simple/Single-line & Potentiometry & $0.4-0.9$ & 90 & Edmonds and Coutts, 1983 \\
\hline & $\mathrm{CaCl}_{2}$ soil extracts & Simple/Single-line & Potentiometry & - & 110 & Hongbo et al., 1985 \\
\hline \multirow[t]{2}{*}{ Phosphorous } & Soil extracts & Simple/Four-line & UV/Vis & $0.4-1.8$ & 120 & Sun et al., 1981 \\
\hline & Soil digests & Simple/Two-line & UV/Vis & 0.97 & 120 & Fang et al., 1982 \\
\hline
\end{tabular}

(continued) 
TABLE 1. Continued.

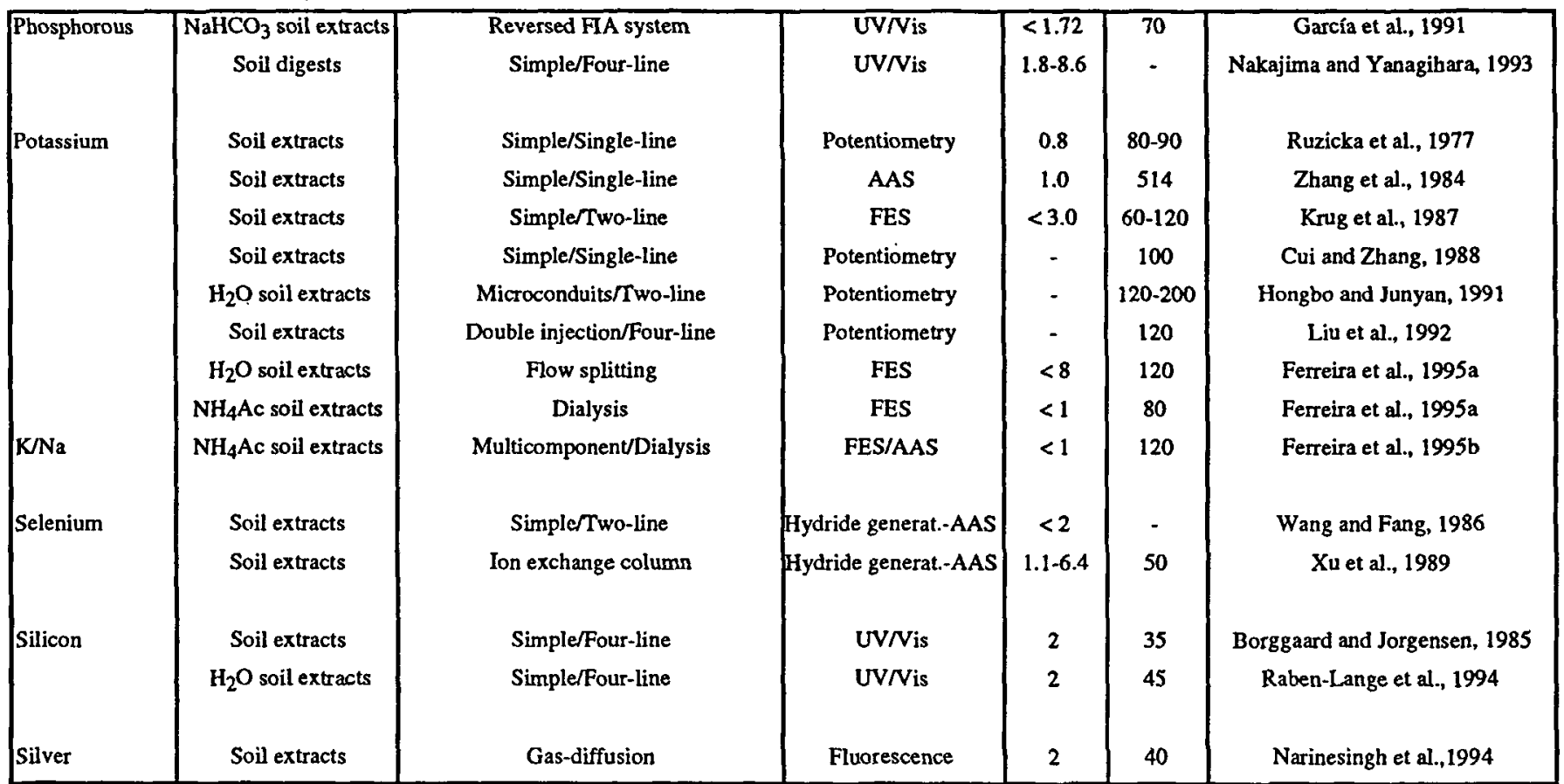




\begin{tabular}{|c|c|c|c|c|c|c|}
\hline \multirow[t]{5}{*}{ Sodium } & Soil extracts & Simple/Single-line & AAS & 1.0 & 514 & Zhang et al., 1984 \\
\hline & Soil extracts & Simple/Two-line & FES & $<3.0$ & $60-120$ & Krug et al., 1987 \\
\hline & $\mathrm{H}_{2} \mathrm{O}$ soil extracts & Mictoconduits $T$ wo-line & Potentiometry & - & $120-200$ & Hongbo and Junyan, 1991 \\
\hline & $\mathrm{H}_{2} \mathrm{O}$ soil extracts & Flow splitting & FES & $<3$ & 120 & Ferreira et al., 1995a \\
\hline & $\mathrm{NH}_{4} \mathrm{Ac}$ soil extracts & Flow splitting & FES & $<2$ & 100 & Ferreira et al., 1995a \\
\hline Sulphate & $\mathrm{H}_{2} \mathrm{O}$ soil extracts & On-line filtration/Merging zones & Turbidimetry-UV/Nis & $<10$ & 120 & Zhi et al., 1994 \\
\hline Technetium-99 & Soil digests & Ion exchange column & ICP-MS & - & - & Hollenbach et al., 1994 \\
\hline Thallium & Soil digests & Simple/Single-line & Amperometry & $7.2-14.3$ & - & Lukaszewski and Zembrzuski, 1992 \\
\hline Thorium-230 & Soil digests & Ion exchange column & ICP-MS & - & - & Hollenbach et al., 1994 \\
\hline Uranium-234 & Soil digests & Ion exchange column & ICP-MS & - & - & Hollenbach et al., 1994 \\
\hline \multirow[t]{2}{*}{ Zinc } & Soil extracts & Simple/Single-line & AAS & 1.0 & 514 & Zhang et al., 1984 \\
\hline & Soil extracts & Simple/Two-line & UV/Vis & 1.4 & 60 & Sun et al., 1985 \\
\hline
\end{tabular}

(a) Relative standard deviations.

(s)Sampling rate. 


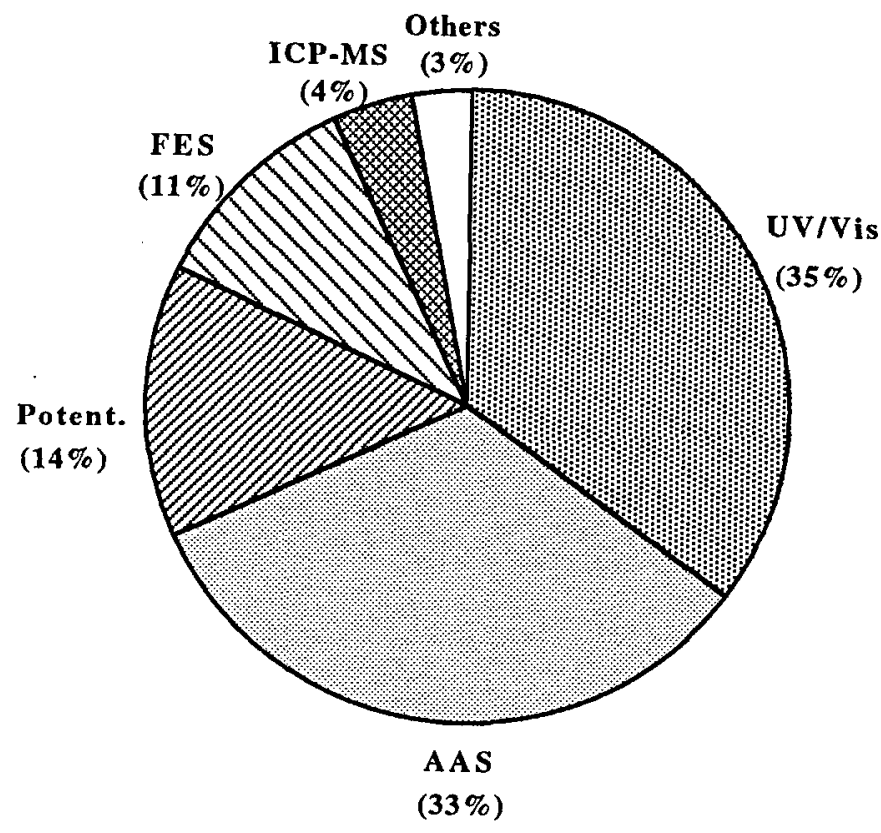

FIGURE 1. Distribution of the detection systems used in FIA systems developed for soil analysis. UV/Vis: UV/Vis Spectrophotometry; AAS: Atomic Absorption Spectrophotometry; Potent.: Potentiometry; FES: Flame Emission Spectrometry; Others: Include Amperometry and Fluorescence.

either a simple coupling of the flow cell on a UV/Vis spectrophotometer or flow tube to the entrance device of an AA spectrophotometer, is made. Fourteen percent of the systems reported, however, use a potentiometric detector. Mechanical difficulties in robustly incorporating these detectors in their conventional configuration into the flow system may be the most important factor that determines their usefulness. Tubular configurations for these detectors minimize these problems as has been reported in some of the procedures developed for soil extract analysis (Ferreira and Lima, 1993).

Flame emission spectrometry is the detection system used in $11 \%$ of the reported papers. Despite benefiting from the same advantages associated to its connection to a FIA system, and as with the FIA-AAS combination, this low percentage is probably due to the fact that this detection system is basically only used in the determination of three alkali elements, sodium $(\mathrm{Na})$, potassium $(\mathrm{K})$, and lithium (Li). 
Amperometry and fluorescence detection systems can also be coupled to the FIA system but with fewer number of applications. They are included in the group identified as "others" in Figure 1.

\section{Cationic Species}

Reis et al. (1979) developed a FIA system with a merging zones approach and sequential addition of pulsed reagents for the spectrophotometric determination of aluminum (Al) in soil potassium chloride (KCL) extracts and plant tissue digests. The manifold consisted of a four channel arrangement where samples and reagents are introduced into the system by a multiple proportional injector. The sample is injected in a water carrier stream and simultaneously with two reagents. After addition of the first reagent for neutralization, the sample plug meets a stream of color reagent (eriochrome cyanine) with the reaction taking place in a mixing coil before merging into a stream carrying the masking agent which is added in a synchronized manner. Detection finally takes place in the flow cell at $535 \mathrm{~nm}$. The $\mathrm{pH}$ of each stream was carefully studied due to the dependence of the reactions on $\mathrm{pH}$. Iron (Fe) interference is minimized with the addition of ascorbic acid, and $\mathrm{SO}_{4}$ interference is not significant due to the high dispersion level in the manifold. This system is able to assay $\mathrm{Al}$ in a range of concentrations between 0 and $20 \mathrm{mg}$ $\mathrm{L}^{-1}$ with a relative standard deviation (RSD) less than $1 \%$ for an $\mathrm{Al}$ concentration of $5.0 \mathrm{mg} \mathrm{L}^{-1}$ and with recoveries between $98-101 \%$.

The determination of $\mathrm{Al}$ in KCL soil extracts was also reported by Downard et al. (1992) who described a FIA procedure involving the formation of an Al(III)-1,2-dihydroxianthraquinone-3-sulphonic acid (DASA) complex at $\mathrm{pH} 9.0$ with ampero-metric measurement of the excess of DASA at $+0.50 \mathrm{~V}$ on a gold electrode. Electrode fouling by the adsorption of DASA oxidation products was minimized by the use of a double pumping system to provide both a reagent cycle and a wash cycle. They described both the advantages and also some drawbacks of this detection system when compared with determinations made spectrophotometrically. The detection limit when using $2 \times 10^{-5} \mathrm{M}$ DASA was $2.5 \times 10^{-7} \mathrm{M} \mathrm{Al}(\mathrm{III})$ and the RSD for $9 \times 10^{-6} \mathrm{M}$ Al(III) was $4.3 \%$.

Hawke and Powell (1994) applied a simple three-line flow injection system with short reaction times for the determination of kinetically-labile Al(III) with spectrophotometric detection. A comparison of the chrome azurol S (CAS), eriochrome cyanine $R(\mathrm{ECR}$ ), and pyrocatechol violet (PCV) techniques was made in a series of complexes with model ligands. A $250-\mu \mathrm{L}$ aliquot of standards and samples was injected in a water carrier stream. A buffer stream of $0.05 \mathrm{M} \mathrm{KCL}$ (pH 5.5) was merged with the chromophore stream and this mixture subsequently merged with the carrier stream for absorbance reading after flowing through a 28-cm mixing coil. Aluminum(III) was determined with a detection limit of 60 $\mathrm{nM}$ and the system showed linear response up to $30 \mu \mathrm{M}$. 
Cadmium (Cd) determination has only been reported by Ma et al. (1994). These authors suggested a flow injection on-line sorbent extraction system with flame atomic absorption spectrometry to determine not only $\mathrm{Cd}$, but also copper $(\mathrm{Cu})$ and lead $(\mathrm{Pb})$ in digests from solid environmental samples. In the extraction stage, the sample was loaded for 20 seconds at $8.7 \mathrm{~mL} \mathrm{~min}^{-1}$ mixed with a complexing reagent DDPA (ammonium diethyldithiophosphate) at $2.2 \mathrm{~mL} \mathrm{~min}^{-1}$ passing through a $(\mathrm{C} 18)$ bounded silica gel column. Then at the elution stage, the column was eluted with methanol pumped by a second peristaltic pump at an elution rate of $4.0 \mathrm{~mL} \mathrm{~min}^{-1}$ against an uptake rate of the nebulizer of $2.0 \mathrm{~mL}$ $\mathrm{min}^{-1}$. The linear detection ranges obtained were of 0.8 to $50,1.4$ to 300 , and 10 to $1,000 \mathrm{mg} \mathrm{L}^{-1}$ of $\mathrm{Cd}, \mathrm{Cu}$, and $\mathrm{Pb}$, respectively. Enhancement factors compared with conventional flame AAS were of 35 for $\mathrm{Cd}$ and $\mathrm{Cu}$ and 26 for $\mathrm{Pb}$.

Several FIA systems have been developed for the determination of $\mathrm{Cd}$ in soil. Jacintho et al. (1981) proposed a FIA system with spectrophotometric detection for the determination of $\mathrm{Ca}$ in $\mathrm{KCL}$ soil extracts, employing glyoxal bis(2-hydroxyanil) as the color-forming agent. The zone-sampling technique was used for adequate dilution of the sample before its injection allowing a dispersion factor of 0.009 . This dispersion factor was evaluated as the ratio between absorbances corresponding to the maximum peak height and to an undispersed dye solution (Reis et al., 1981). After selecting a well defined small zone of the sample, it was injected in a second carrier and a merging zones technique was used for reagent addition. After the confluence of sample and reagent streams, mixing took place in a mixing chamber and the red complex was formed just before its concentration was made at $555 \mathrm{~nm}$.

Another system for the determination of $\mathrm{Ca}$ in soil extracts, but with AAS detection, was suggested by Zhang et al. (1984). The simple FIA system makes use of the merging zones technique for the addition of a lanthanum (La) solution for saving of this reagent [consumption of $\mathrm{La}$ (III) was about $1 \%$ of that of the manual method]. After the merging of the sample and reagent streams, the mixture was directed into the detector through a $40-\mathrm{cm}$ flow tube. This same system was not only applied for the determination of $\mathrm{Ca}$, but also for the determination of $\mathrm{Mg}$ in concentration ranges of $0-30 \mathrm{mg} \mathrm{L}^{-1}$ and $0-10 \mathrm{mg} \mathrm{L}^{-1}$, respectively, for the two cations.

Also using AAS detection, Krug et al. (1987) suggested a FIA system based on the injection of a $5 \mu \mathrm{L}$ of sample into a water carrier stream which merged with another stream for the addition of either a La or strontium (Sr) reagent for minimizing interferences, and then further mixed with water before reaching the detector. This same system was also applied for the determination of $\mathrm{Mg}$, but as the dispersion level was not sufficient for this cation, the authors rotated the AAS spectrophotometer burner head $30^{\circ}$ which, however, resulted in a loss of sensitivity. This FIA-AAS system could determine $\mathrm{Ca}$ in a range from 0 to $1,000 \mathrm{mg} \mathrm{L}^{-1}$ and $\mathrm{Mg}$ in a range of 0 to $500 \mathrm{mg} \mathrm{L}^{-1}$ in the analyte without requiring previous treatment of the samples. 
The same detection system (AAS) was used by Ferreira et al. (1995a) in two different manifolds for the determination of $\mathrm{Ca}$ in soils in both the water soluble and available forms. Both systems were developed in order to allow for in-line dilution of the extracts to adjust the Ca concentration of any soil sample to the working linear concentration range of the detection system as well as provide for the addition of reagents for the minimization of interferences. For water-soluble $\mathrm{Ca}$, a very simple three-line manifold was used. Part of the injected extract was discarded at a splitting point while the remaining portion, after merging with a $\mathrm{La}$ solution in a confluence point, was passed through the detector, the determinable range being 3 to $200 \mathrm{mg} \mathrm{Ca} \mathrm{L}^{-1}$. The system for the determination of available $\mathrm{Ca}$ (ammonium acetate extracted) had a much higher dilution factor which was achieved by using a dialysis unit. The remaining plug in the donor stream was discarded while the acceptor stream carrying the small part of the plug that diffused through the membrane was led to the detector after merging with a confluent stream of $\mathrm{La}$. This system could determine available $\mathrm{Ca}$ between 57 and 2,250 $\mathrm{mg} \mathrm{L} \cdot$.

The first publication reporting on the development of a FIA system for the multicomponent analysis of several species present in soil extracts was by Fang et al. (1985). A gradient scanning standard addition flow injection technique was applied for the simultaneous flame spectrophotometric determination of $\mathrm{Ca}, \mathrm{Li}$, $\mathrm{Na}$, and $\mathrm{K}$ in an ammonium acetate soil extract as well as in tap water. A fast scanning mono-chromator and a storage oscilloscope were employed to obtain the spectra in the $350-800 \mathrm{~nm}$ range in different sections of the injected sample zone which optimized the intensity ranges for all analytes. Standard solutions without an internal reference were used as the carrier solution and were directed to waste during the sampling stage, while distilled water was aspirated into the burner. When the valve was turned, the sample was propelled by the standard carrier stream with water preceding the sample zone with the standard solution being gradually dispersed into the sample zone. Sampling rates were limited by the data storage of the oscilloscope and the speed of the recorder which was slow. However, the method described showed the feasibility of such an approach, with the possibility that the sampling frequency could be much increased by storing and processing the collected analytical data by computer.

Cardwell et al. (1988) applied a single-line manifold connected to a potentiometric sensor cell and a data acquisition system which was constructed for the simultaneous determination of $\mathrm{Ca}, \mathrm{K}, \mathrm{Cl}$, and nitrate $\left(\mathrm{NO}_{3}\right)$. The sensor membranes were of valinomycin for $\mathrm{K}$, neutral carrier ETH 1001 for $\mathrm{Ca}$, tetradodecylammonium nitrate for $\mathrm{NO}_{3}$, and $\mathrm{Cl}$ determined with an $\mathrm{Ag} / \mathrm{AgCl}$ electrode. Sodium acetate $\left(\mathrm{NaC}_{2} \mathrm{H}_{3} \mathrm{O}_{2}\right)$ soil extracts $(30 \mu \mathrm{L})$ were injected in a solution of $\mathrm{NaC}_{2} \mathrm{H}_{3} \mathrm{O}_{2}$-containing potassium nitrate $\left(\mathrm{KNO}_{3}\right)$ and calcium chloride $\left(\mathrm{CaCl}_{2}\right)$. Calibration graphs showed linearity down to near $1 \times 10^{-4} \mathrm{M}$ of each ion.

A FIA system for the simultaneous determination of $\mathrm{Ca}$ and $\mathrm{Mg}$ was proposed by Ferreira et al. (1995b) using two AA spectrophotometers placed in parallel. 
The major manifold characteristic was a dialysis unit for division of the injected soil extract into two streams. The extract $(240 \mu \mathrm{L})$ was injected into a carrier stream and led to the dialysis unit. The analyte that diffused to the acceptor channel which was then directed to a confluence for the addition of $\mathrm{La}$, flowing towards the detector for $\mathrm{Mg}$ determination. The plug remaining in the donor stream was diluted by withdrawing part of it at a splitting point while the rest was led to the detector after a confluence of La. The sensitivity of this determination was decreased by rotating the burner head about $30^{\circ}$. This system could make 100 determinations per hour for these pair of ions in the range of 40 to $2,500 \mathrm{mg}$ of Ca per $\mathrm{kg}$ of dry soil and 10 to $350 \mathrm{mg}$ of $\mathrm{Mg}$ per $\mathrm{kg}$ of dry soil, thus covering the full range of concentrations usually found in soils.

The same paper reported on the optimization of the previous FIA system for the determination of both $\mathrm{Ca}$ and $\mathrm{K}$ by AA and flame emission spectrometry, respectively. In this case, the different dilution levels demanded by each cation led to the determination of $\mathrm{K}$ from the donor stream and $\mathrm{Ca}$ from the acceptor stream. The values for the flow rates and tube lengths were adjusted for this particular pair of ions in order to adjust the concentration of these ions to that expected to be found in soil to the linear concentration intervals of the detectors. The optimized manifold could perform 80 determinations per hour for both ions in the range of 0.5 to $500 \mathrm{mg}$ of $\mathrm{K}$ per $\mathrm{kg}$ dry soil and 100 to $2,500 \mathrm{mg}$ of Ca per $\mathrm{kg}$ dry soil.

Another FLA set-up for the determination of both $\mathrm{Ca}$ and $\mathrm{Mg}$ in $\mathrm{KCL}$ soil extracts was proposed by Nogueira et al. (1996) by resorting to a relocatable detector. In this type of configuration, a multielement determination is attained based on the possibility of moving one detector to a different manifold site by making it relocate from one monitoring site to another (Zagatto et al., 1992). The color reagent was o-cresolphtalein complexion (CPC), ammonium/ammonia was the buffer system, and EGTA or 8-hydroxyquinoline was the masking agents for $\mathrm{Ca}$ and $\mathrm{Mg}$, respectively. By switching the injector-commutator, $100 \mu \mathrm{L}$ aliquot of sample was introduced into the carrier stream (KCL for matrix matching purposes) which received the buffer/masking solution and the CPC reagent before flowing through a $100-\mathrm{cm}$ mixing coil where the color was developed. The resulting transient signal was proportional to the $\mathrm{Mg}$ content in the sample which was monitored at $575 \mathrm{~nm}$. After reaching the maximum signal, the injector-commutator was switched again, receiving a second plug $(35 \mu \mathrm{L})$ of the same sample into another $\mathrm{KCL}$ carrier stream. The aliquot was similarly treated but with the addition of a modified reagent and a different masking agent. The treated sample was monitored at the same wavelength, yielding a transient signal proportional to the $\mathrm{Ca}$ concentration. Recoveries between 97.5 and $104.1 \%$ were obtained after adding $100 \mathrm{~mL}$ of $\mathrm{Ca}$ at $15 \mathrm{mg} \mathrm{L}^{-1}$ or $\mathrm{Mg}$ at $5.0 \mathrm{mg} \mathrm{L}^{-1}$ to $50-\mathrm{mL}$ sample solutions.

Only one reference concerning the determination of chromium $(\mathrm{Cr})$ was found. Jorgensen and Regitano (1980) proposed a manifold where the mixing of the 
color development reagent (1,5-diphenylcarbazide) and sulphuric acid $\left(\mathrm{H}_{2} \mathrm{SO}_{4}\right)$ (for $\mathrm{pH}$ adjustment) took place before injection of $30 \mu \mathrm{L}$ of the soil extract. A $50-\mathrm{cm}$ tube separated the injection point from the spectrophotometric detector set to $540 \mathrm{~nm}$, which was sufficient for proper color development. The authors presented different combinations for flow rates of the two channels as a way of obtaining different dispersion levels, thus different sensitivities. The system can determine $\mathrm{Cr}(\mathrm{VI})$ in a concentration range of 0.1 to $20 \mathrm{mg} \mathrm{L}^{-1}$.

Copper determination in soil samples by FIA was reported in two articles, the first by Zhang et al. (1984), who presented a simple single-line flow system where the water carrier stream was aspirated into the nebulizer of an AA spectrophotometer (aspiration rate of $6.0 \mathrm{~mL} \mathrm{~min}^{-1}$ ). Only a $5-\mathrm{cm}$ tube separated the injection point from the nebulizer entrance. With this system it was possible to determine $\mathrm{Cu}$ in a range from 0 to $6 \mathrm{mg} \mathrm{L}^{-1}$. The same system was applied for the determination of iron $(\mathrm{Fe})$, manganese $(\mathrm{Mn})$, and $\mathrm{K}$ in a concentration range of 0 to $10 \mathrm{mg} \mathrm{L}^{-1}$ and also zinc $(\mathrm{Zn})$ and $\mathrm{Na}$ in a range of 0 to $2 \mathrm{mg} \mathrm{L}^{-1}$.

The other system is described by $\mathrm{Ma}$ et al. (1994) for the determination of $\mathrm{Cu}$, $\mathrm{Cd}$, and $\mathrm{Pb}$ in soil digests which has already been described earlier for the determination of $\mathrm{Cd}$.

The determination of $\mathrm{Fe}$ in soils was first presented by Cui and Fang (1984) using UV/Vis spectrophotometry as detection system. Hydrochloric acid ( $\mathrm{HCl}$ )-soluble Fe was determined as the complex of Fe(II) with 2,2'-bipyridyl(I). A $30 \mu \mathrm{L}$ aliquot of extract was injected in a previously de-aerated carrier stream of potassium hydrogenphtalate $(\mathrm{pH} 4)$ containing iodine (I) and ascorbic acid and flowing towards the flow cell for detection at $540 \mathrm{~nm}$. The system could make Fe determinations in a range of 0.02 to $7 \mathrm{mg} \mathrm{L}^{-1}$ in the injected soil extracts.

Ferreira et al. (1996b) more recently described another FIA system using colorimetric detection for the determination of $\mathrm{Fe}$ in soil extracts based on the formation of the colored complex produced from the reaction of $\mathrm{Fe}$ (II) with 1,10-phenanthroline. Samples and standards were injected in a water carrier stream that merged towards a stream of ascorbic acid in $\mathrm{HCl}$ for the reduction of $\mathrm{Fe}$ (III) to $\mathrm{Fe}(\mathrm{II})$. This stream was mixed with the color development reagent at a confluence point before detection at $508 \mathrm{~nm}$. The authors discussed problems due to the influence of the refraction index (Schlieren signal) observed from the injection of the soil extracts which was solved by using a large injection volume $(540 \mu \mathrm{L})$ that allowed the formation of three distinct areas: two refractive index peaks at the extremes of a well defined plateau whose height was taken as the analytical signal. The system covered the Fe concentration range of 1 to $10 \mathrm{mg}$ $\mathrm{L}^{-1}$.

The same authors (Ferreira et al., 1998) proposed an alternative single-line system for Fe determination with AAS detection. The use of FIA as a way of introducing the extracts into the AA spectrophotometer worked as a way of overcoming the blockage of the burner head which was observed with the 
conventional introduction. The system allowed the determination of $\mathrm{Fe}$ within the range of 0.36 and $5 \mathrm{mg} \mathrm{L}^{-1}$ without requiring any pretreatment of the extracts. The sample throughput rate was 300 samples hour-1.

Only one work reported the determination of $\mathrm{Pb}$ in soils by FIA. Ma et al. (1994) developed a FIA on-line sorbent extraction with flame AAS for the determination of $\mathrm{Pb}, \mathrm{Cd}$, and $\mathrm{Cu}$. This system was already described for the determination of $\mathrm{Cd}$.

Resorting to AAS detection, Zhang et al. (1984) and Krug et al. (1987) suggested a FIA technique for the determination of $\mathrm{Mg}$ which were also previously described for the determination of $\mathrm{Ca}$.

Ferreira et al. (1995a) suggested another FIA-AAS system for the determination of water-soluble $\mathrm{Mg}$, but instead of resorting to the injection of an extremely small volume as done by Krug et al. (1987), the authors manipulated the flow rates of a splitting and a confluence stream to achieve the necessary dilution of the samples. The splitting, to discard part of the injected volume $(240 \mu \mathrm{L})$, and the confluence to contribute for dispersion and also for the addition of the $\mathrm{La}$ (III) solution. This joint effect allowed a dispersion level of 12-fold and the determination of $\mathrm{Mg}$ in a concentration range between 0.2 and $20 \mathrm{mg} \mathrm{L}^{-1}$.

In the same work, the authors reported on another system for the determination of $\mathrm{Mg}$ in the both available or extractable forms. Since the amount of available $\mathrm{Mg}$ was about 300 times higher than the linear response limit of the AAS for this element, the system had to provide for a very high dilution capability. The authors developed a FIA system with a dialysis unit, in which the donor stream was discarded and the acceptor stream delivered to the detector after merging with a stream of $\mathrm{La}$ (III) solution. In this flow system, determination of $\mathrm{Mg}$ is within the range of 15 to $400 \mathrm{mg} \mathrm{L}^{-1}$.

This approach was reported later by the same authors (Ferreira et al., 1995b) with another procedure where the FIA system was developed for the simultaneous determination of both $\mathrm{Mg}$ and $\mathrm{Na}$ using AAS and a flame emission spectrometer as detectors, respectively. The donor stream merged to a confluence of water not only to increase the dilution level, but also to adjust the final flow rate to the normal uptake rate of the flame photometer for the detection of $\mathrm{Na}$. As much higher dilution levels were necessary for the $\mathrm{Mg}$ determination, this one was drawn from the acceptor stream after converging with a stream of $\mathrm{La}$ (III) for interference treatment. In this system, determinations of $\mathrm{Na}$ is in a range of 0.02 to $350 \mathrm{mg}$ $\mathrm{kg}^{-1}$ and between 19 and $400 \mathrm{mg} \mathrm{kg}^{-1}$ for $\mathrm{Mg}$ in dry soil.

Two papers reported FIA systems for the determination of manganese (Mn) in soils, one using AAS and the other using UV/Vis spectrophotometry as the detection devices. Zhang et al. (1984) presented the system already described for $\mathrm{Cu}$ consisting of a single-line manifold in which samples and standards were injected in a water carrier stream aspirated into the nebulizer of an AA spectrophotometer. 
The system described by Mesquita et al. (1989) is based on permanganate formation for detection at $548 \mathrm{~nm}$, applied for determination of $\mathrm{Mn}$ in soils, plants, and rocks. The soil extracts were injected in a $\mathrm{HCl}$-carrier stream merging with a stream containing the oxidant/catalyst reagent. The oxidation reaction by periodate took place along a $400-\mathrm{cm}$ length coil immersed in a boiling water bath to keep the temperature of the coil at $95^{\circ} \mathrm{C}$. The stream then passed by a debubbler and cooled along another coil before reaching the detector. The rate of this reaction was accelerated by exploiting the autocatalytic effect which is enhanced with the addition of permanganate in the confluent stream. The detection limit of this system was about $0.3 \mathrm{mg} \mathrm{Mn} \mathrm{L}$.

Two papers reported on the FIA determination of $\mathrm{pH}$ in soils. The first by Edmonds and Coutts (1983) described a FIA system for the determination of $\mathrm{pH}$ in filtered $\mathrm{CaCl}_{2}$ extracts. Samples $(500 \mu \mathrm{L}$ ) were injected in a carrier (a buffer at $\mathrm{pH} 5.54$ ) flowing at $0.9 \mathrm{~mL} \mathrm{~min}^{-1}$. A 5-cm flow tube separated the injection point from the detector (a pH electrode), finally flowing to a beaker where the reference electrode was placed. System dispersion was minimal and the carrier role was as a transporter of the extracts and also as a stabilizer of the electrode.

Hongbo et al. (1985) described another FIA manifold for $\mathrm{pH}$ measurement in soil extracts and critically evaluated the parameters affecting this type of determination. They incorporated a tubular PVC-based $\mathrm{pH}$-sensitive membrane electrode in a single-line flow system with a minimum dispersion coefficient. In order to obtain reliable results, the authors stated that it is necessary to have a dispersion coefficient $D_{\max } \leq 1.008$ at peak maximum and to adjust the buffering capacity of the carrier to be less than that of the sample solution. This is achieved by injecting $350 \mu \mathrm{L}$ samples into a carrier with $\mathrm{pH}=4.9$ and with a buffering capacity of $2.9 \times 10^{-5}$ flowing at $2.0 \mathrm{~mL} \mathrm{~min}^{-1}$ which allowed for sampling rates of 110 determinations per hour and with high reproducibility. This membrane was also applied in FIA microconduits allowing a throughput of 200 samples per hour.

A large number of papers describing different FIA systems for the determination of $\mathrm{K}$ in soils have been reported. The first one published was by Ruzicka et al. (1977). This in fact was the first work where a potentiometric detector was applied in FIA methodology. The authors described a one-line flow system with potentiometric detection using a commercially available valinomycine $\mathrm{K}$-selective electrode. The $\mathrm{NaC}_{2} \mathrm{H}_{3} \mathrm{O}_{2}$ soil extracts $(200 \mu \mathrm{L})$ were injected in a $\mathrm{NaC}_{2} \mathrm{H}_{3} \mathrm{O}_{2}$ stream and carried along a $65-\mathrm{cm}$ tube. After passing by the electrode membrane, the stream flowed to a reservoir where the reference electrode was placed and the level of this reservoir was maintained constant by differential pumping. The same flow system has been applied for the determination of $\mathrm{K}$ in blood serum.

Krug et al. (1987) developed a FIA manifold with AAS detection for the determination of $\mathrm{K}$ in soil extracts. This same system was also applied for the determination of $\mathrm{Na}$ in the same matrix. It consisted of a two-line manifold where the extracts $(250 \mu \mathrm{L}$ for $\mathrm{K}$ and $50 \mu \mathrm{L}$ for $\mathrm{Na})$ were injected in a water carrier stream. To this stream was added a $250 \mathrm{mg} \mathrm{L}^{-1}$ sodium chloride $(\mathrm{NaCl})$ or a 250 
$\mathrm{mg} \mathrm{L}^{-1} \mathrm{KCL}$ buffer in a confluence for masking interferences. Concentrations between 0 and $10 \mathrm{mg} \mathrm{L}^{-1}$ were determined for either of the two cations.

Cui and Zhang (1988) proposed a FIA system with potentiometric detection for the determination of $\mathrm{K}$ in hydrochloric acid $(\mathrm{HCl})$ soil extracts. The selective electrode was a PVC tubular flow-through valinomycin membrane. The samples and extracts $(350 \mu \mathrm{L})$ were injected in a HCl-triethanolamine carrier (pH 8.5) containing $0.1 \mathrm{mg} \mathrm{K} \mathrm{L}^{-1}$ for stabilization of the baseline. The detection limit of this system was $0.05 \mathrm{mg} \mathrm{K} \mathrm{L}^{-1}$.

Another flow system with potentiometric detection was presented by Hongbo and Junyan (1991) consisting of a $\mathrm{K}, \mathrm{Na}$, and $\mathrm{Cl}$ integrated microconduits device, where these ions were determined separately. The operational conditions were of $100 \mu \mathrm{L}$ for the sampling volume, $2.0 \mathrm{~mL} \mathrm{~min}^{-1}$ for the flow rate at the indicator tubular electrode and $0.24 \mathrm{~mL} \mathrm{~min}^{-1}$ for the flow rate at the reference electrode. This system was applied for the determination of these ions in water soil extracts, water, and serum.

Liu et al. (1992) described a flow injection system which had two ion-selective electrodes arranged in parallel to serve as detectors for both $\mathrm{K}$ and $\mathrm{NO}_{3}$. These two ions could be detected by using a double sample loop and an asynchronous sample injection technique. The carrier stream channels of the electrodes alternated between the sampling and the sample injection modes. The potential of the electrodes of the sample in the sampling stage was kept constant which served as the reference electrode. The selective electrodes potential between injections was stabilized by adding a small concentration of each analyte to be determined in the carrier solution, thus allowing the electrode membrane to be always in contact with the respective ion. Determinations of $\mathrm{K}$ and $\mathrm{NO}_{3}$ were performed in a range of 0.8 to $6,000 \mathrm{mg} \mathrm{L}^{-1}$ and 0.3 to $3,500 \mathrm{mg} \mathrm{L}^{-1}$, respectively.

Ferreira et al. (1995a) reported two FIA systems using flame emission spectrometry as the detection technique, one for the determination of water-soluble $\mathrm{K}$ and the other for the ammonium acetate-soluble form. In the first system, the dispersion level necessary to adjust the concentration of any soil extract to the linear range of the flame photometer was achieved simply by disposing part of the injected sample in a splitting point and leading the remaining towards the detector. This approach allowed determinations in a range between 2.5 and 300 $\mathrm{mg} \mathrm{K} \mathrm{L}{ }^{-1}$. The second system was developed had a much higher dilution level which was achieved by providing the FIA system with a dialysis unit, an approach already described for the determination of $\mathrm{Ca}$ and $\mathrm{Mg}$. Potassium was determined in the range of 0.5 to $1,100 \mathrm{mg} \mathrm{L}^{-1}$. Both systems were optimized in order to allow for the injection of any soil sample without requiring previous treatment or dilution of the extracts.

The same authors (Ferreira et al., 1995b) also proposed a system with a dialysis unit for the simultaneous determination of both $\mathrm{K}$ and $\mathrm{Na}$ by flame emission spectrometry. Sodium was determined in the stream flowing from the donor channel and $\mathrm{K}$ from the acceptor channel as the necessary dispersion level was 
much higher for $\mathrm{K}$ (dispersion levels of 13 for $\mathrm{Na}$ and of 86 for $\mathrm{K}$ were achieved). The stream flowing from the donor channel converged with a stream of water before reaching the nebulizer and the flow rate was set in order to impose an overpressure over the nebulizer as a final adjustment of the sensitivity. The stream flowing from the acceptor stream also merged with a stream of water, but in this case only to set the input rate close to the photometer aspiration rate. Potassium was then determined between 1.7 and $1,000 \mathrm{mg} \mathrm{kg}^{-1}$ and $\mathrm{Na}$ between 0.95 and $500 \mathrm{mg} \mathrm{kg}^{-1}$ in dry soil.

Wang and Fang (1986) reported a FIA system for the determination of trace levels of selenium (Se) with hydride-generation atomic absorption spectrophotometric detection. The system was applied to soil, plants, and waste waters. An aliquot of the sample was injected into a $\mathrm{HCl}$ carrier solution. Following passage through a mixing coil, Se was reduced by a $\mathrm{NaBH}_{4}$ solution added at a confluence point. The $\mathrm{H}_{2} \mathrm{Se}$ formed in the reaction coil was mixed with argon and was then swept into a gas-liquid separator as $\mathrm{H}_{2} \mathrm{Se}$ to be determined by AAS at $700^{\circ} \mathrm{C}$. The detection limit of this system was of $0.07 \mathrm{ng} \mathrm{Se} \mathrm{mL}^{-1}$.

A similar system for the determination of ultra-trace levels of Se(IV) in water-soluble soil extracts as well as in natural waters was described by Xu et al. (1989) using an on-line preconcentration column. Selenium was adsorbed on two parallel miniature basic ion-exchange columns fixed on a 8-channel rotary multi-functional valve to achieve the concentration of two samples simultaneously. Sample solutions merged with a flowing acetate buffer solution (pH 5.0) before passing through the ion-exchange columns. The Se adsorbed on the columns was eluted sequentially through a two-way valve into the flow injection hydride generation system with $1 \mathrm{~mol} \mathrm{HCl} \mathrm{L}^{-1}$ and merged with a reductant $\left(0.5 \% \mathrm{NaBH}_{4}\right.$ in $0.1 \% \mathrm{NaOH})$. The detection limit of this system was of $0.002 \mu \mathrm{g} \mathrm{Se} \mathrm{L}^{-1}$.

Sodium is another cation of great interest in routine soil analyses and several procedures describing the development of FIA systems for this determination have been reported. Several of these systems have already been described reporting on the determination of other ions (Zhang et al., 1984; Krug et al., 1987; Hongbo and Junyan, 1991). Multicomponent analysis of this ion combined with others have also been described in this text (Fang et al., 1985; Ferreira et al., 1995b).

Two FIA systems have been reported by Ferreira et al. (1995a) for the determination of water-soluble and ammonium acetate-soluble $\mathrm{Na}$, both with flame emission spectrometry detection. For water extracts, a $240 \mu \mathrm{L}$ aliquot is injected into a water carrier stream flowing at $12.4 \mathrm{~mL} \mathrm{~min}^{-1}$. Part of the dispersed plug is removed in a splitting point at a rate of $7.4 \mathrm{~mL} \mathrm{~min}^{-1}$ which results in a flow rate at the nebulizer entrance close to the normal uptake rate for the flame photometer. This simple system allows for determinations of soluble $\mathrm{Na}$ between 0.3 and 300 $\mathrm{mg} \mathrm{L}^{-1}$. The other system provides for a higher dilution which is achieved by increasing the level of splitting (thus discarding more of the sample plug) and also by adding to the previous system a confluent stream of water after the splitting point. Available $\mathrm{Na}$ can be determined between 2.5 and $300 \mathrm{mg} \mathrm{L}^{-1}$. 
Two systems for the determination of $\mathrm{Zn}$ have been reported, the first by $\mathrm{Zhang}$ et al. (1984) with AAS detection which has already been described for the determination of $\mathrm{Ca}$. The other by Sun et al. (1985) consists of a two-line arrangement where a $240 \mu \mathrm{L}$ aliquot of sample is injected into a carrier stream followed by the addition of a dithizone solvent for $\mathrm{Zn}$ extraction with color development occurring in a $200-\mathrm{cm}$ mixing coil before detection at $535 \mathrm{~nm}$. The system can make $\mathrm{Zn}$ determinations in a range between 0.015 and $5 \mathrm{mg} \mathrm{L}^{-1}$.

\section{Anionic Species}

A FIA system with potentiometric detection was suggested by Van Staden (1987) for the determination of inorganic bromide $(\mathrm{Br})$ in synthetic soil extracts. Samples were taken from the turntable of an automatic sampler, and $30 \mu \mathrm{L}$ were injected in a carrier stream [ $1 \mathrm{M}$ potassium nitrate $\left.\left(\mathrm{KNO}_{3}\right)\right]$. The injected samples were mixed with the carrier stream in a 105-cm mixing coil and suffered the addition of another stream of $1 \mathrm{M} \mathrm{KNO}_{3}$. After flowing through a second mixing coil of $160 \mathrm{~cm}$, the potential was measured in a laboratory-made coated tubular $\mathrm{Br}$ electrode with the reference electrode dipped in a waste beaker at the end of the flow system. Chloride interferences were overcome by fixing the interference in the baseline which was achieved by adding $100 \mathrm{mg} \mathrm{L}^{-1}$ of $\mathrm{Cl}$ in both $\mathrm{KNO}_{3}$ solutions. The method was suitable for the determination of $\mathrm{Br}$ in the range 1-5,000 mg L $\mathrm{L}^{-1}$.

Two papers reporting the development of FIA systems for the determination of water-soluble $\mathrm{Cl}$ in soils with potentiometric detection have been presented. The first by Hongbo and Junyan (1991) consisting of an integrated microconduit potentiometric analytical system with a tubular coated ion-selective electrode, applied not only for soil, but also for water and serum analysis. A sample aliquot of $100 \mu \mathrm{L}$ was injected in a carrier stream $\left(10^{-5} \mathrm{M} \mathrm{Cl}\right)$ flowing towards the flow-through cell for potential reading. The indicator and the reference electrodes were connected with a micro three-way tube. This system allowed sampling rates between 120 and 200 determinations per hour.

The other system was suggested by Ferreira et al. (1996a), describing a single channel FIA manifold for the potentiometric pseudo-titration of water-soluble $\mathrm{Cl}$ using a tubular silver $(\mathrm{Ag})$ ion-selective electrode with a homogeneous crystalline membrane of silver sulfide $\left(\mathrm{Ag}_{2} \mathrm{~S}\right)$ as the potentiometric detector. Standards and soil extracts $(180 \mu \mathrm{L})$ were injected in a carrier stream $\left[5.0 \times 10^{-5} \mathrm{M}\right.$ silver nitrate $\left(\mathrm{AgNO}_{3}\right), 10^{-3} \mathrm{M}$ nitric acid $\left(\mathrm{HNO}_{3}\right)$, and $\left.0.2 \mathrm{M} \mathrm{KNO}_{3}\right]$ where the dispersion of the plug and the precipitation of Ag cation occurred. An Ag concentration gradient was generated in a mixing chamber with a volume of $300 \mu \mathrm{L}$ and this gradient was monitored at the tubular electrode. A relation between the peak width versus the logarithm of $\mathrm{Cl}$ concentration was established and $\mathrm{Cl}$ was determined in a range between 1 and $100 \mathrm{mg} \mathrm{L}^{-1}$ which includes the whole range of $\mathrm{Cl}$ concentration expected to be found in this matrix. 
A flow method for the turbidimetric determination of soluble $\mathrm{SO}_{4}$ has been described by Zhi et al. (1994). The FIA system was coupled to a on-line filtration probe designed in order to simplify the sample pretreatment. To avoid interferences of organic matter with the developed method, the samples were mixed with activated charcoal before extraction of the $\mathrm{SO}_{4}$. The soil suspension was aspirated to pass through the filtration probe, followed by a debubbler unit for removal of air bubbles before feeding the injection loop of the flow system. A volume of 200 $\mu \mathrm{L}$ of filtrate and of $36 \mu \mathrm{L}$ of supplementary $\mathrm{SO}_{4}$ solution was introduced in a merging zones mode and was then mixed with the reagent (barium-arabic gum- $\mathrm{HCl}$ solution) added in a confluence. The reaction of precipitation of barium sulphate $\left(\mathrm{BaSO}_{4}\right)$ took place in a mixing coil before spectrophotometric detection at 400 $\mathrm{nm}$. This system allowed the determination of this anion between 2 and $180 \mathrm{mg}$ $\mathrm{L}^{-1}$ with little pretreatment of the samples.

\section{Nitrogen Compounds}

In most soils the bulk of $\mathrm{N}$ is in organic forms and usually near the surface. The inorganic forms of $\mathrm{N}$ include nitrate $\left(\mathrm{NO}_{3}\right)$ which is soluble and easily leached or taken up; nitrite $\left(\mathrm{NO}_{2}\right)$ which is usually a transitional stage between $\mathrm{NO}_{3}$ and ammonium $\left(\mathrm{NH}_{4}\right) ; \mathrm{NH}_{4}$ which occurs as the easily removed exchangeable ion and also in more unavailable fixed forms as well as traces of gaseous forms such as $\mathrm{N}_{2}$, nitrogen monoxides, and elemental $\mathrm{N}$.

Several works describing FIA systems for the determination of $\mathrm{N}$ in its different forms in soils were reported. The first by Ruzicka et al. (1977) for the determination of $\mathrm{NO}_{3}$ in soil extracts with potentiometric detection. The electrode consisted of a membrane based on tetraoctylammonium bromide dissolved in dibutyl phthalate and incorporated in PVC. The inner reference solution was composed of $1 \times 10^{-2} \mathrm{M}$ sodium nitrate $\left(\mathrm{NaNO}_{3}\right)$ and $1 \times 10^{-2} \mathrm{M}$ sodium chloride $(\mathrm{NaCl})$. The FIA system was a confluent stream arrangement where $300 \mu \mathrm{L}$ of sample was injected in a phosphate buffer carrier solution that then merged with another stream of the same composition for a better mixing and hence a better stabilization of the $\mathrm{pH}$. The mixture took place in a 1.4-m mixing coil and after passing by the membrane of the $\mathrm{NO}_{3}$-selective electrode, and the stream flowed to a reservoir where the reference electrode was dipped. The lowest $\mathrm{NO}_{3}$ detection limit obtained was approximately $1 \times 10^{-5} \mathrm{M}$.

Krug et al. (1979) described a turbidimetric procedure for the determination of ammonia $\left(\mathrm{NH}_{3}\right)$ in low concentrations with the use of Nessler's reagent. An aliquot of $30 \mu \mathrm{L}$ of soil digest was injected in a carrier stream of $2 \mathrm{M}$ sodium hydroxide $(\mathrm{NaOH})$ solution which then met another stream of a mixture of Nessler's reagent and $2 \mathrm{M} \mathrm{NaOH}$. This mixture took place in a reaction coil before reaching the detector set at $420 \mathrm{~nm}$. The advantage of this system was the possibility of injecting acid samples (provided by the procedures for digestion of the soils) without affecting the colored turbidity formed. This system allowed the determination of 
ammonia $\left(\mathrm{NH}_{3}\right)$ in soil digests and in water samples in a range of $0.5-6.0 \mathrm{mg} \mathrm{L}^{-1}$ of $\mathrm{NH}_{4}-\mathrm{N}$, but this method could not be applied if a significant amount of colloidal material was present in the solutions to be analyzed.

Schalscha et al. (1981) evaluated the potentiometric FIA system described by Ruzicka et al. (1977) for the determination of $\mathrm{NO}_{3}$ in saturated soil extracts and compared this methodology with the Bremner reduction-distillation method and the Cd-reduction method, respectively. Several advantages of the FIA method were reported specifically concerning the lower volume of sample, the short analysis time, and the low investment in equipment involved in the application of this method in laboratories of soil routine analysis.

The first FIA system for the determination of total $\mathrm{N}$ in soils was suggested by Sun et al. (1981a). The digests $(230 \mu \mathrm{L})$ were injected in a carrier of alkaline phenol solution where it was neutralized. An alkaline sodium hypochlorate solution flowing at the same rate was then added in a confluence and the color development reaction took place before detection at $625 \mathrm{~nm}$. The authors described some problems associated with the variety of acidities in the different soil digests, for what they recommended a controlled possible loss of $\mathrm{H}_{2} \mathrm{SO}_{4}$ during the digestion process. They also recommended that the quantity of $\mathrm{Cu}$ catalyst added for the digestion process should be kept as constant as possible since the $\mathrm{Cu}$ color can affect the detection. The detection limit of this system was of $0.5 \mathrm{mg} \mathrm{N} \mathrm{L}^{-1}$.

A gas-diffusion FIA system with colorimetric detection was proposed by Sun et al. (1986) also for the determination of total N. Samples and soil digests (100 $\mu \mathrm{L}$ ) were injected in a water carrier that converged with a $\mathrm{NaOH}$ stream for conversion of $\mathrm{NH}_{4}$ into $\mathrm{NH}_{3}$ gas. This gas passed across a gas-permeable membrane to an acceptor stream where it reacted with an indicator prepared in a buffer solution, to result in $\mathrm{NH}_{4}$ and a change in the color of the indicator. Absorbance was then read at $590 \mathrm{~nm}$. Different working ranges were obtained depending on the concentration of the buffer solution. Several problems of interferences reported in previous works were overcome by the use of the gas-diffusion unit that permitted the disposal of some interfering species that could not cross the hydrophobic membrane.

Shirato et al. (1989) described different FIA systems with UV/Vis spectrophotometric detection for determination of $\mathrm{N}$ in several forms. For the determination of $\mathrm{NO}_{2}, 40 \mu \mathrm{L}$ of $\mathrm{N}$-(1-naphthyl) ethylenediamine reagent was injected into a water carrier solution on either end of the sample solution by using a 16-port valve. This stream then passed along a reaction coil towards the detector and absorbance was measured at $520 \mathrm{~nm}$. Nitrate was determined similarly after reduction to $\mathrm{NO}_{2}$ on a 30-cm Cu-Cd-glass column. For $\mathrm{NH}_{4}$ determination, $\mathrm{NH}_{3}$ was liberated by $200 \mu \mathrm{L}$ of a $1 \mathrm{M} \mathrm{NaOH}$ solution injected in both sides of the sample solution, separated with a dialysis membrane and determined by the indophenol method in the acceptor stream. Absorbance was measured at $630 \mathrm{~nm}$. These systems allowed the determination of $\mathrm{NO}_{2}, \mathrm{NO}_{3}$, and $\mathrm{NH}_{4}$ in the range of 0.1 to $7 \mathrm{mg} \mathrm{L}^{-1}, 1$ to $20 \mathrm{mg} \mathrm{L}^{-1}$, and 1 to $150 \mathrm{mg} \mathrm{L}^{-1}$, respectively. 
Sullivan and Havlin (1991) described a FIA system developed for the determination of urea- $\mathrm{N}$ in $\mathrm{KCl}$ soil extracts, based on the diacetyl monoxime thiosemicarbazide colorimetric method with a modified acid reagent that increased the rate of color formation. The reagents were all mixed along the flow system before merging with the carrier stream $(2 \mathrm{M} \mathrm{KCl}$ solution) which carried the 310 $\mu \mathrm{L}$ of injected extract. The streams were mixed in a mixing coil immersed in a $95^{\circ} \mathrm{C}$ water bath and detection of the formed colored complex took place at 520 $\mathrm{nm}$. The reagents of this method were modified for this FIA system and optimized to allow the determination of urea-N up to $8 \mathrm{mg} \mathrm{L}^{-1}$ with a detection limit of 0.01 $\mathrm{mg} \mathrm{L} \mathrm{L}^{-1}$.

Raigon et al. (1992) described two FIA manifolds with spectrophotometric detection for the determination of available $\mathrm{N}$ in the nitric and ammoniacal forms. For the $\mathrm{NH}_{4}-\mathrm{N}$, a reversed FIA system was used. A stream of ammonium chloride $\left(\mathrm{NH}_{4} \mathrm{Cl}\right)$ solution merged with a stream of soil extract and this mixture acted as carrier. The Nessler's reagent $(110 \mu \mathrm{L})$ was injected into this carrier stream and the colored product formed was monitored at $415 \mathrm{~nm}$. Ammonium-N was determined in the range of 0.02 to $4 \mathrm{mg} \mathrm{L}^{-1}$. The system for determination of $\mathrm{NO}_{3}-\mathrm{N}$ was a normal FIA system in which $10 \mu \mathrm{L}$ of the soil extract was injected into a carrier of ammonium chloride $\left(\mathrm{NH}_{4} \mathrm{Cl}\right)$ with the $\mathrm{NO}_{3}$ being reduced to $\mathrm{NO}_{2}$ on-line during the passage of the sample plug in a Cd-reductor column. Nitrites then reacted with acidic sulphanilamide and $\mathrm{N}$-(1-naphtyl)-ethylenediamine dihydrochloride added in a confluence, and the color development reaction took place in a $75-\mathrm{cm}$ tube before the purple product was detected at $540 \mathrm{~nm}$. Nitrate-N was detected in a range between 0.10 and $8 \mathrm{mg} \mathrm{L}^{-1}$.

Liu et al. (1992) proposed an ion-selective electrode flow system with two electrodes arranged in parallel in the manifold for the determination of $\mathrm{NO}_{3}$ and $\mathrm{K}$. This system was already described in this text for the determination of $\mathrm{K}$.

Another system resorting to UV/Vis spectrophotometry was described by Alves et al. (1993) for determination of $\mathrm{NH}_{4}$ in $\mathrm{KCl}$ extracts based on the salicylatehypochlorite colorimetric reaction. Samples and standards were injected in a water carrier stream and reagents were added in confluences along the flow system. The reaction took place in a $200-\mathrm{cm}$ mixing coil immersed in a $70^{\circ} \mathrm{C}$ water bath and the colored product flowed towards the flow cell of the spectrophotometer for absorbance reading at $647 \mathrm{~nm}$. Important care was given to control the water bath temperature which should not vary more than $\pm 0.1^{\circ} \mathrm{C}$ for stable and reproducible results. This technique is capable of quantifying $\mathrm{NH}_{4}$ to concentrations as low as $0.05 \mathrm{mg} \mathrm{NH}_{4}-\mathrm{N} \mathrm{L}^{-1}$ (equivalent to $0.25 \mathrm{mg} \mathrm{NH}_{4}-\mathrm{N} \mathrm{g}^{-1} \mathrm{dry}$ soil).

Nakajima and Yanagihara (1993) reported a FIA system for the colorimetric determination of $N$ using a gas-diffusion unit. The digests $(30$ to $200 \mu \mathrm{L})$ were injected in $\mathrm{H}_{2} \mathrm{SO}_{4}$ carrier stream that merged with a confluence for the addition of a $\mathrm{NaOH}$ for conversion of $\mathrm{NH}_{4}$ into $\mathrm{NH}_{3}$. This conversion takes place in a $100-\mathrm{cm}$ mixing coil heated at $30^{\circ} \mathrm{C}$. The gas crossed a gas-permeable membrane to an acceptor stream of an indicator for detection at $590 \mathrm{~nm}$. 
Another FIA system incorporating a gas-diffusion unit but with a potentiometric detector was recently developed by Ferreira et al. (1996c) for the determination of total $\mathrm{N}$ in soil digests and was presented as an alternative to the distillation/ titration step in the Kjeldahl method. The solutions, obtained from the Kjeldahl digestion of the soil samples, were injected $(180 \mu \mathrm{L})$ in a water carrier stream which directed the plug to a confluence where $\mathrm{a} \mathrm{NaOH}$ solution which was added for conversion of $\mathrm{NH}_{4}$ into $\mathrm{NH}_{3}$. While passing along the gas-permeable membrane, the $\mathrm{NH}_{3}$ gas diffused to an acceptor buffer stream of Tris $\mathrm{HCl}(\mathrm{pH}$ 7.5) responsible for the reconversion of the $\mathrm{NH}_{3}$ gas which was finally led towards the $\mathrm{NH}_{4}$ ion-selective electrode. The selectivity of the electrode sensor system provided the final selection between the $\mathrm{NH}_{3}$ gas already converted into $\mathrm{NH}_{4}$ and the other gaseous species that might have passed through the membrane. The potentiometric detector was a PVC tubular selective electrode without inner reference solution and with the sensor system composed of nonactin/monactin in tris (2-ethylexyl) phosphate. The construction of this electrode was also described. This system allowed direct introduction of any soil Kjeldahl digest and determinations in a concentration range between 0.05 and $0.6 \%$ of $\mathrm{N}$ in dry soil.

A multicomponent system for the determination of $\mathrm{NO}_{2}-\mathrm{NO}_{3}$ was suggested by $\mathrm{Xu}$ and Fang (1983) by resorting to the simultaneous injection of the extract in two different channels. The system was based on the reaction of $\mathrm{NO}_{2}$ with alfanaphthylamine-7-sulphonic acid and sulphanilamide with spectrophotometric detection at $520 \mathrm{~nm}$. A Cd-coated $\mathrm{Zn}$ reductor column was included in one of the channels of the flow system for a previous in-line reduction of $\mathrm{NO}_{3}$ to $\mathrm{NO}_{2}$. The detection limits achieved were of $10 \mu \mathrm{g} \mathrm{L}^{-1}$ for $\mathrm{NO}_{3}-\mathrm{N}$ and of $1 \mu \mathrm{g} \mathrm{L}^{-1}$ for $\mathrm{NO}_{2}-\mathrm{N}$.

Another system for this multicomponent determination was described by Karlicek et al. (1988) based on the same reaction of the $\mathrm{NO}_{2}$ with alfa-naphthylamine-7-sulphonic acid and sulphanilamide with absorbance reading of the red dye. Nitrates were determined the same way after in-line reduction by metallic Cd. Concentration ranges of $0.02-2 \mathrm{mg} \mathrm{L}^{-1}$ for $\mathrm{NO}_{2}$ and of $0.5-20 \mathrm{mg} \mathrm{L}^{-1}$ for $\mathrm{NO}_{3}$ were determined.

\section{Phosphorus Compounds}

Four papers report the development of FIA systems for the determination of $\mathrm{P}$ in soils. In all of them, the authors resorted to the same color development reaction based of the formation of the molybdate blue, but different approaches for the flow injection manifold were described.

In the manifold described by Sun et al. (1981b) for determining available $P$, the extracts $(560 \mu \mathrm{L})$ were injected in a reductor carrier [stannous chloride $\left(\mathrm{SnCl}_{2}\right)$ ] that flowed towards a confluence for addition of the color development reagent (molybdate). The reaction took place in a mixing coil before detection at $650 \mathrm{~nm}$. Relative standard deviations of $1.8 \%$ and $0.4 \%$ were obtained for 25 injections of extracts with $\mathrm{P}_{2} \mathrm{O}_{5}$ concentrations of 0.46 and of $0.8 \mathrm{mg} \mathrm{L}^{-1}$, respectively. 
Fang et al. (1982) described a very similar flow system for determination of total $\mathrm{P}$, where only $25 \mu \mathrm{L}$ of sample was injected. The absorbance of the color complex was monitored at $700 \mathrm{~nm}$. The main purpose of this work was to achieve a better detection limit for this determination and they obtained a detection limit of $0.05 \mathrm{mg} \mathrm{P} \mathrm{L}^{-1}$.

García et al. (1991) developed a reversed flow injection system for the determination of assimilable $\mathrm{P}$ in $0.5 \mathrm{M}$ sodium bicarbonate $\left(\mathrm{NaHCO}_{3}\right)$ soil extracts. The selection of a reversed FIA approach in which the extract runs in the system as the carrier solution with the reagents (molybdate in acidic solution and tin chloride) being added in confluences, had the main objective of overcoming problems of unstable baseline reported by other authors. The authors described additional advantages such as the increase in sensitivity and the lower reagents consumption. The extracts (with a previous 1:10 dilution) flowing in the flow tube were added $119.5 \mu \mathrm{L}$ of the reagents mixture injected in this stream. The color development reaction took place in a flow tube before detection at $660 \mathrm{~nm}$. Linearity was obtained up to $0.8 \mathrm{mg} \mathrm{PL}^{-1}$ and the detection limit was of $0.025 \mathrm{mg}$ $\mathrm{PL}^{-1}$.

Nakajima and Yanagihara (1993) described a FIA system for total $P$ in which the soil digests $(30-200 \mu \mathrm{L})$ were injected into $\mathrm{a}_{2} \mathrm{SO}_{4}$ carrier to mix successively with ammonium molybdate solution, water, and finally ascorbic acid before detection at $660 \mathrm{~nm}$. All these streams were added in confluences followed by reaction coils for appropriate mixture and reactions. The authors reported the possibility of determining 100 samples in three days from the weighing operation till the end of the analysis.

\section{Other Species}

Wang and Wang (1992) reported a system for the determination of antimony $\mathrm{(Sb)}$ and also arsenic (As) and bismuth (Bi) by FIA hydride generation graphite furnace AAS. The samples were injected in a stream consisting of a mixture of $\mathrm{HCl}, \mathrm{HNO}_{3}$, and $\mathrm{H}_{2} \mathrm{SO}_{4}$ which merged with a stream of $\mathrm{NaBH}_{4}$ in $\mathrm{NaOH}$. The mixture passed to a gas-liquid separator where the generated hydrides were carried to the graphite-furnace by a stream of argon flowing at $250 \mathrm{~mL} \mathrm{~min}^{-1}$ for AAS determination of $\mathrm{As}, \mathrm{Sb}$, and $\mathrm{Bi}$. Recoveries were of 94 to $99 \%$ and detection limits of $6.29,9.21$, and $3.77 \mathrm{pg}$ for $\mathrm{As}, \mathrm{Sb}$, and $\mathrm{Bi}$, respectively.

Three papers describe systems for the determination of boron (B). The first by Sun et al. (1983) based on the reaction of B with azomethine-H with colorimetric detection. The system consisted of a three channel configurations where reagents were added in confluences and allowed to mix in long mixing coils before detection at $415 \mathrm{~nm}$. This system throughput was of 60 samples per hour in a concentration range of 0.02 to $5 \mathrm{mg} \mathrm{B} \mathrm{L}^{-1}$.

López-Garcia et al. (1988) described two FIA manifolds, one normal and one a reversed system, both based on the formation of a blue ternary complex between the anionic complex of boric acid $\left(\mathrm{H}_{3} \mathrm{BO}_{3}\right)$ with 2,6-dihydroxybenzoic acid 
(DHBA) and crystal violet. As the formation of the B-DHBA complex is slow $(10 \mathrm{~min}$ at $\mathrm{pH} 1.0)$, they needed to be mixed before injection into the manifold. In the normal FIA system, $35 \mu \mathrm{L}$ of this mixture were injected into a water carrier stream. This stream merged with a stream of reagent solution [crystal violet, poly(vinyl alcohol) and a $\mathrm{pH} 2.6$ buffer solution], following to the detector set at $490 \mathrm{~nm}$. This system could determine $B$ in a range between 0.02 and $0.5 \mathrm{mg} \mathrm{L}^{-1}$. In the reversed FIA system, $135 \mu \mathrm{L}$ of the reagent solution were injected into a carrier (B-DHBA-complex), and the product detected at $590 \mathrm{~nm}$. With this system, linearity was obtained between 0.05 and $0.5 \mathrm{mg} \mathrm{B} \mathrm{L}^{-1}$.

Carrero et al. (1993) described a time-based injector for B determination applied to soil and plant analyses. The extract solution plus azomethine- $\mathrm{H}$ and phosphate buffer ( $\mathrm{pH}$ 6.9) containing EDTA were mixed in a ratio of $3: 1: 1$ in a mixing coil and passed to a $47-\mathrm{cm}$ holding coil using a suction device. The time-based injector delivered electronic pulses to a two-way solenoid valve which closed the tube from the suction device injecting $150 \mu \mathrm{L}$ of the mixture into a water carrier stream flowing towards the detector were absorbance was measured at $420 \mathrm{~nm}$. When the analysis of each sample was completed, the system was cleaned by circulating $0.1 \mathrm{M} \mathrm{HCl}$ solution through the sample line for at least 30 seconds. As the sample and reagents were not consumed during the stoppage of the sample zone, there was a considerable saving. This set-up allowed determinations in a concentration range between 0.5 and $6 \mathrm{mg} \mathrm{B} \mathrm{L}^{-1}$.

Zhang et al. (1987) modified a flow system for the determination of mercury $(\mathrm{Hg})$ in aqueous solutions developed by Andrade et al. (1984) in order to apply it to the determination in soil and improve the detection limit, sampling frequency as well as to increase the lifetime of the PTFE membrane. The method involved permeation of $\mathrm{Hg}$ vapor through the PTFE membrane which separated the flow cell from the optical path of the spectrophotometer. Absorption was read at 253.7 $\mathrm{nm}$. The detection limit achieved was $0.06 \mu \mathrm{g} \mathrm{Hg} \mathrm{L}^{-1}$ with a sampling rate of 200 samples per hour. The coefficient of variation was of $1 \%$ for a concentration of $\mathrm{Hg}$ of $4 \mu \mathrm{g} \mathrm{L} \mathrm{L}^{-1}$.

Narinesingh et al. (1994) described another FIA system for trace $\mathrm{Hg}$ and $\mathrm{Ag}$ determinations but based on the inhibitory effect that these ions have on the enzymatic reaction of urease which converts urea to carbon dioxide $\left(\mathrm{CO}_{2}\right)$ and $\mathrm{NH}_{3}$. The liberated $\mathrm{NH}_{3}$ was monitored fluorimetrically. An aliquot of $90 \mu \mathrm{L}$ of sample was injected into a phosphate-buffered urease ( $\mathrm{pH}$ 7.0) carrier stream and mixed successively with the urea and $\mathrm{NaOH}$ reagent streams. The reaction mixture passed through a gas-separation unit where the enzymatically-generated $\mathrm{NH}_{3}$ diffused through a PTFE membrane and was collected in a stream of o-phthaldehyde(I) and mercaptoethanol in borate buffer solution ( $\mathrm{pH} \mathrm{10.2).} \mathrm{The}$ resulting fluorophore- $\mathrm{NH}_{3}$ adduct was then determined at $455 \mathrm{~nm}$ (excitation at $340 \mathrm{~nm}$ ). Soil extracts were analyzed within a concentration range from 2 to 22 $\mu \mathrm{g} \mathrm{L}^{-1}$ and from 0.1 to $1.0 \mu \mathrm{g} \mathrm{L}^{-1}$ of $\mathrm{Hg}$ and $\mathrm{Ag}$, respectively, with a coefficient of variation of $2 \%$. 
Trace molybdenum (Mo) determination in soil extracts and water samples was reported in one work from Guo et al. (1993) by a FIA inductively coupled plasma spectrometry (ICP-AES). The concentration step took place in-line, in a microion-exchange column where samples were injected with ammonium chloride/ ammonium citrate as the eluent flowing at $0.5 \mathrm{~mL} \mathrm{~min}^{-1}$ and at $60^{\circ} \mathrm{C}$ over $5 \mathrm{~min}$. The eluate was then carried to the spectrophotometer with argon as carrier gas for ICP-AES detection. Recoveries between 90 and $110 \%$ were obtained for $12 \mathrm{ng}$ Mo L ${ }^{-1}$.

A FIA procedure for the determination of silicon ( $\mathrm{Si}$ ) based on the molybdenum blue formation by reduction of $B$-molybdosilicate by ascorbic acid was described by Borggaard and Jorgensen (1985). Different extractors [NaOH, dithionite-EDTA solution, and hydrogen fluoride (HF)] were used and tested especially to evaluate the capacity to minimize interferences. The extracts $(300 \mu \mathrm{L})$ were injected in a water carrier stream that converged into three consecutive confluences for addition of ammonium molybdate, oxalic acid, and ascorbic acid solution. Between each addition long mixing coils $\left(5,2\right.$, and $5 \mathrm{~m}$, respectively) immersed in a $80^{\circ} \mathrm{C}$ water bath assured the development of reactions before detection at $816 \mathrm{~nm}$. The authors reported the formation of air bubbles in the FIA system due to the high temperature and suggested a de-aeration of the solutions before use as a way to reduce their effect. All extracts had to be diluted before injection. A rate of 35 determinations per hour was obtained with a detection limit of $30 \mathrm{ng} \mathrm{Si} \mathrm{mL}^{-1}$ and a linear limit of $1.0 \mathrm{mg} \mathrm{Si} \mathrm{L}^{-1}$.

A similar system, based on the same colorimetric reaction was optimized by Raben-Lange et al. (1994) for the determination of water-soluble Si, but with reduction of $\mathrm{PO}_{4}$ interference. Detection took place at $790 \mathrm{~nm}$. The reactions developed at room temperature, thus avoiding problems due to the formation of bubbles observed in previous method without compromising the sensitivity of the system as determinations in a concentration range between 0.04 and $20 \mathrm{mg} \mathrm{Si}$ $\mathrm{L}^{-1}$ were obtained. However, the authors recommended de-gassing of solutions and samples before use. At the same time, interferences from $\mathrm{PO}_{4}$ were reduced up to 15 -fold excess of this anion and the sampling rate was improve to 45 determinations per hour.

A FIA mini-column was used for pre-concentration of technetium-99, thorium-230, and uranium-234 added to soil samples followed by detection by ICP-AES (Hollenbach et al., 1994). Advantage was taken from the FIA technique for reproducible concentration of the samples and introduction in the detection system, allowing detection limits of $11 \mathrm{mBq} \mathrm{g}^{-1}\left(0.02 \mathrm{ng} \mathrm{g}^{-1}\right), 3.7 \mathrm{mBq} \mathrm{g}^{-1}(0.005$ ng g $\left.{ }^{-1}\right)$, and $0.74 \mathrm{mBq} \mathrm{g}^{-1}\left(0.003 \mathrm{ng} \mathrm{g}^{-1}\right)$ for $99 \mathrm{Tc}, 230 \mathrm{Th}$, and $234 \mathrm{U}$, respectively.

Lukaszewski and Zembrzuski (1992) resorted to a FIA system for the determination of thallium (Th) in soils with differential pulse anodic stripping voltammetry as detection process in a method that did not require any separation prior to determination. The interferences of $\mathrm{Fe}, \mathrm{Al}$, and $\mathrm{Mn}$ were removed by media exchange performed in the FIA system and the other interferences were 
removed by the use of the base electrolyte consisting of $0.015 \mathrm{M} \mathrm{EDTA}$ and $0.1 \mathrm{M}$ ascorbic acid. Limited deposition time, connected to the volume of analyte was a drawback in using a FIA system, but this was overcome by using circulation of the analyte during the time necessary for effective preconcentration of Th. Determinations were performed in a concentration range from 100 to $350 \mu \mathrm{g}$ Th $\mathrm{L}^{-1}$.

\section{ACKNOWLEDGMENTS}

The authors gratefully acknowledge financial support from JNICT through project PEAM/C/TAI/259/93. One of the authors (A.M.R. Ferreira) expresses his thanks for grant PRAXIS XXI BD/5363/95.

\section{REFERENCES}

Alves, B.J.R., R.M. Boddey, and S.S. Urquiaga. 1993. A rapid and sensitive flow injection technique for the analysis of ammonium in soil extracts. Commun. Soil Sci. Plant Anal. 24(3-4):277-284.

Andrade, J.C., C. Pasquini, N. Baccan, and J.C. Van-Loon. 1983. Cold-vapor atomic absorption determination of mercury by flow-injection analysis using a Teflon-membrane phase separator coupled to the absorption cell. Spectrochim. Acta 38 (10):1329-1338.

Appelqvist, R., G.R. Beecher, H. Bergamin Fo, G. Den Boef, J. Emnéus, Z. Fang, L. Gorton, E.H. Hansen, P.E. Hare, J.M. Harris, J.J. Harrow, N. Ishibashi, J. Janata, G. Johanson, B. Karlberg, F.J. Krug, W.E. Van der Linden, M.D. Luque de Castro, G. Marko-Varga, J.N. Miller, H.A. Mottola, H. Muller, G.E. Pacey, C. Riley, J. Ruzicka, R.C. Schothorst, K.K. Stewart, A. Townshend, J.F. Tyson, K. Ueno, M. Valcarcel, J. Vanderslice, P.J. Worsfold, N. Yoza, and E.A.G. Zagatto. 1986. Flow injection analysis (FIA)-A personal view. Anal. Chim. Acta 180:1-67.

Borggaard, O.K. and S.S. Jorgensen. 1985. Determination of silicon in soil extracts by flow injection analysis. Analyst 110:177-180.

Burguera, J.L. 1989. Flow Injection Atomic Spectroscopy. Marcel Dekker, Inc., New York, NY.

Cardwell, T.J., R.W. Cattrall, and P.C. Hauser. 1988. A multi-ion sensor cell and data-acquisition system for flow injection analysis. Anal. Chim. Acta 214:359-366.

Carlson, R.M., R.I. Cabrera, J.L. Paul, J. Quick, and R.Y. Evans. 1990. Rapid determination of ammonium and nitrate in soil and plant tissue extracts. Commun. Soil Sci. Plant Anal. 21(13-16):1519-1529.

Carrero, P., J.L. Burguera, M. Burguera, and C. Rivas. 1993. A time-based injector applied to the flow injection spectrophotometric determination of boron in plant materials and soils. Talanta 40(12):1967-1974. 
Catalayud, J.M. 1985. Aplicaciones del FIA a muestras de interés agrícola. Tec. Lab. 120:18-24.

Cui, H. and Z. Fang. 1984. Flow-injection analysis of iron in soil extracts. Fenxi Huaxue 12(8):759-761.

Cui, H. and S. Zhang. 1988. Preparation of PVC-tubular flow-through valinomycinmembrane potassium ion-selective electrode and its application in flow-injection analysis. Fenxi Huaxue 16(4):320-323.

Downard, A.J., H.K.J. Powell, and S. Xu. 1992. Flow-injection analysis for aluminium with indirect amperometric detection. Anal. Chim. Acta 256:117-123.

Edmonds, T.E. and G. Coutts. 1983. Flow injection analysis system for determining soil pH. Analyst 108:1013-1017.

Fang, Z. 1993. Flow Injection Separation and Preconcentration. VCH, Weiheim, Germany.

Fang, Z., J.M. Harris, J. Ruzicka, and E.H. Hansen. 1985. Simultaneous flame photometric determination of lithium, sodium, potassium, and calcium by flow injection analysis with gradient scanning standard addition. Anal. Chem. 57:1457-1461.

Fang, Z., L. Sun, Z. Gao, Y. Zhu, X. Wang, and L. Li. 1982. Determination of total phosphorous in soil digests by flow injection analysis. Turang Tongbao 4:40-42.

Ferreira, A.M.R., A.O.S.S. Rangel, and J.L.F.C. Lima. 1995a. Flow injection systems with a stream splitting and a dialysis unit for the soil analysis of sodium and potassium by flame emission spectrometry, and calcium and magnesium by atomic absorption spectrophotometry. Commun. Soil Sci. Plant Anal. 26(1-2):183-195.

Ferreira, A.M.R., J.L.F.C. Lima, and A.O.S.S. Rangel. 1995b. Flow injection simultaneous determination of basic cation pairs in soils. Soil Sci. 159(5):331-336.

Ferreira, A.M.R., A.O.S.S. Rangel, and J.L.F.C. Lima. 1996a. Determination of chloride in soils by flow injection potentiometric titration. Commun. Soil Sci. Plant Anal. 27(5-8):1437-1445.

Ferreira, A.M.R., A.O.S.S. Rangel, and J.L.F.C. Lima. 1996b. Colorimetric determination of available iron in soils by flow injection analysis. Analysis 24:343-346.

Ferreira, A.M.R., J.L.F.C. Lima, and A.O.S.S. Rangel. 1996c. Potentiometric determination of total nitrogen in soils by flow injection analysis with a gas-diffusion unit. Aust. J. Soil Res. 34:503-510.

Ferreira, A.M.R., J.L.F.C. Lima, and A.O.S.S. Rangel. 1998. Determination of iron in soils by flow injection atomic absorption spectrometry. Commun. Soil Sci. Plant Anal. (submitted). 
Ferreira, I.M.P.L.V.O. and J.L.F.C. Lima. 1993. Tubular electrodes and other devices for potentiometric detection in FIA. J. Flow Injection Anal. 10(1):17-32.

García, M.P., R. Puchades, and A.M. Catala. 1991. Determination of assimilable phosphorus in soils by reversed flow injection analysis. Soil Sci. 151(5):349-354.

Gentry, C.E. and R.B. Willis. 1988. Improved method for automated determination of ammonium in soil extracts. Commun. Soil Sci. Plant Anal. 19(6):721-737.

Guo, L., G.L. Zhang, and Z.L. Fang. 1993. Determination of trace molybdenum by online ion-exchange pre-concentration with a flow injection inductively coupled plasma atomic emission spectrophotometric system. Guangpuxue Yu Guangpu Fenxi 13(5):73-76.

Hawke, D.J. and H.K.J. Powell. 1994. Flow-injection analysis applied to the kinetic determination of reactive (toxic) aluminium: Comparison of chromophores. Anal. Chim. Acta 299:257-268.

Hollenbach, M., J. Grohs, S. Mamich, M. Kroft, and E.R. Denoyer. 1994. Determination of technetium-99, thorium-230 and uranium-234 in soils by inductively coupled plasma mass spectrometry using flow injection preconcentration. J. Anal. Atom. Spectro. 9(9):927-933.

Hongbo, C. and S. Junyan. 1991. Potassium sodium chloride integrated microconduits in a potentiometric analytical system. Talanta 38(9):989-993.

Hongbo, C., E.H. Hansen, and J. Ruzicka. 1985. Evaluation of critical parameters for measurement of $\mathrm{pH}$ by flow injection analysis. Anal. Chim. Acta 169:209-220.

Jacintho, A.O., E.A.G. Zagatto, B.F. Reis, L.C.R. Pessenda, and F.J. Krug. 1981. Merging zones in flow injection analysis. Part 6 . Determination of calcium in natural waters, soil and plant materials with glyoxal bis(2-hydroxyanil). Anal. Chim. Acta 130:361-368.

Jorgensen, S.S. and M.A.B. Regitano. 1980. Rapid determination of chromium (VI) by flow injection analysis. Analyst 105:292-295.

Karlberg, B. and G.H. Pacey. 1989. Flow Injection Analysis-A Practical Guide. Elsevier Science, Amsterdam, The Netherlands.

Karlicek, R., J. Dolejsova, and M. Polasek. 1988. Simultaneous determination of nitrites and nitrates by flow-injection analysis. Agrochemia 28(4):119-122.

Keay, J. and P.M.A. Menage. 1969. Automated distillation procedure for the determination of nitrogen. Analyst 94:895-899.

Krug, F.J., J. Ruzicka, and E.H. Hansen. 1979. Determination of ammonia in low concentrations with Nessler's reagent by flow injection analysis. Analyst 104:47-54. 
Krug, F.J., E.A.N. Fernandes, I.A. Rufini, L.C.R. Pessenda, and A.O. Jacintho. 1987. Sistemas de injeccao em fluxo para a determinaçao de $\mathrm{Ca}, \mathrm{Mg}, \mathrm{Na}$ e $\mathrm{K}$ em águas, plantas, rochas e sedimentos por espectrometria de absorçao e emissao atómica. Quim. Nova 10(3):165-170.

Lea, R. and C.G. Wells. 1980. Determination of extractable sulphate and total sulphur from plant and soil material by an autoanalyzer. Commun. Soil Sci. Plant Anal. 11(5):507-516.

Li, S. and K.A. Smith. 1984. The rapid determination of nitrate at low concentrations in soil extracts: Comparison of ion-selective electrode with continuous-flow analysis. Commun. Soil Sci. Plant Anal. 15(12):1437-1451.

Liu, R.M., D.J. Liu, and A.L. Sun. 1992. Potentiometric detection in flow injection without use of a conventional reference electrode. Analyst 117(8):1335-1337.

López-Garcia, I.L., C.S. Sánchez-Pedreno, M.H. Hernándes-Córdoba, and A.G. Garcia-Lorente. 1988. Determination of boron in plants, soils and waters by flow injection analysis. Analysis 16(9-10):196-200.

Lukaszewski, Z. and W. Zembrzuski. 1992. Determination of thallium in soils by flow injection differential pulse anodic stripping voltammetry. Talanta 39(3):221-227.

Luque de Castro, M.D. and M. Valcárcel. 1990. Novel flow injection approaches to environmental analysis. Int. J. Environ. Anal. Chem. 38:171-183.

Ma, R., W. Van Mol, and F. Adams. 1994. Determination of cadmium, copper and lead in environmental samples. An evaluation of flow injection on-line sorbent extraction for flame atomic absorption spectrometry. Anal. Chim. Acta 285(1):33-43.

Markus, D.K., J.P. McKinnon, and A.F. Buccafuri. 1985. Automated analysis of nitrite-, nitrate-, and ammonium-nitrogen in soils. Soil Sci. Soc. Am. J. 49:1208-1215.

McLeod, S. 1992a. Micro-distillation unit for use in continuous flow analyzers. Its construction and use in determination of ammonia and nitrate in soils. Anal. Chim. Acta 266:107-112.

McLeod, S. 1992b. Determination of total soil and plant nitrogen using a micro-distillation unit in a continuous flow analyzer. Anal. Chim. Acta 266:113-117.

Mesquita, M., A.O. Jacintho, E.A.G. Zagatto, and R.F. Antonio. 1989. Autocatalysis in the spectrophotometric flow-injection determination of manganese as permanganate: Soil, plant and rock analysis. J. Brasilian Chem. Soc. 1:28-34.

Nakajima, $\mathrm{H}$. and R. Yanagihara. 1993. Rapid determination of $\mathrm{HClO}_{4} \cdot \mathrm{H}_{2} \mathrm{SO}_{4}$ degradation nitrogen and phosphorus in farm soils, crops and organic manure using flow injection analysis. J. Flow Injection Anal. 10(2):224-235. 
Narinesingh, D., R. Mungal, and T.T. Ngo. 1994. Screening method for trace mercury analysis using flow injection with urease inhibition and fluorescence detection. Anal. Chim. Acta 292(1):185-190.

Nogueira, A.R.A., S.M.B. Brienza, E.A.G. Zagatto, J.L.F.C. Lima, and A.N. Araújo. 1996. Flow injection system with multi-site detection for spectrophotometric determination of calcium and magnesium in soil extracts and natural waters. J. Agric. Food Chem. 44:165-169.

Raben-Lange, B., A.B. Bendtsen, and S.S. Jorgensen. 1994. Spectrophotometric determination of silicon in soil solutions by flow injection analysis: Reduction of phosphate interference. Commun. Soil Sci. Plant Anal. 25(19\&20):3241-3256.

Raígon, M.D., M.P. García, A. Maquieira, and R. Puchades. 1992. Determination of available nitrogen (nitric and ammoniacal) in soils by flow injection analysis. Analysis 20:483-487.

Reis, B.F., H. Bergamin F', E.A.G. Zagatto, and F.J. Krug. 1979. Merging zones in flow injection analysis. Part 3. Spectrophotometric determination of aluminium in plant and soil materials with sequential addition of pulsed reagents. Anal. Chim. Acta 107:309-317.

Reis, B.F., A.O. Jacintho, J. Moratti, F.J. Krug, E.A.G. Zagatto, H. Bergamin $\mathrm{F}^{\circ}$, and L.C.R. Pessenda. 1981. Zone-sampling processes in flow injection analysis. Anal. Chim. Acta 123:221-228.

Ruzicka, J. and E.H. Hansen. 1975. Flow injection analyses. Part I. A new concept of fast continuous flow analysis. Anal. Chim. Acta 78:145-157.

Ruzicka, J. and E.H. Hansen. 1988. Flow Injection Analysis. John Wiley, New York, NY.

Ruzicka, J., E.H. Hansen, and E.A. Zagatto. 1977. Flow injection analysis. Part VII. Use of ion-selective electrodes for rapid analysis of soil extracts and blood serum. Determination of potassium, sodium and nitrate. Anal. Chim. Acta 88:1-16.

Schalscha, E.B., T. Schirado, and I. Vergara. 1981. Flow injection analysis of nitrate in soil extracts. Evaluation of a nitrate-selective flow electrode method. Soil Sci. Soc. Am. J. 45:446-448.

Selmer-Olsen, A.R. 1971. Determination of ammonium in soil extracts by an automated indophenol method. Analyst 96:565-568.

Shirato, F., Y. Okajima, C. Maekoya, and Y. Takata. 1989. Determination of nitrite, nitrate and ammonium nitrogen in soil by FIA (flow-injection analysis). Bunseki Kagaku 38(9):413-418.

Skeggs, L.T. 1957. An automated method for colorimetric analysis. Am. J. Clin. Path. 28:311-322. 
Sullivan, D.M. and J.L. Havlin. 1991. Flow injection analysis of urea nitrogen in soil extracts. Soil Sci. Soc. Am. J. 55:109-113.

Sun, L.J., Z. Gao, L. Li, and Z. Fang. 1981a. The determination of total nitrogen in soil digests by flow injection analysis. Turang Tongbao 5:38-39.

Sun, L., Z. Gao, X. Yu, and Z. Fang. 1981b. The flow injection analysis of available phosphorous in soils. Fenxi Hauxue 9:586-588.

Sun, L., Z. Sun, and Z. Fang. 1983. The determination of soil available boron with azomethine-H by a flow injection spectrophotometric method. Turang Tongbao 5:41-43.

Sun, L., L. Li, and Z. Fang. 1985. Flow injection analysis of soil available zinc by solvent extraction with dithizone. Fenxi Huaxue 13:447-449.

Sun, L., L. Li, and Z. Fang. 1986. Determination of total nitrogen in soil digests by gas diffusion flow injection analysis. Turang Tongbao 17:37-38.

Tel, D.A. and C. Heseltine. 1990a. The analysis of $\mathrm{KCl}$ soil extracts for nitrate, nitrite and ammonium using a TRAACS 800 analyser. Commun. Soil Sci. Plant Anal. 21(13-16):1681-1688.

Tel, D.A. and C. Heseltine. 1990b. Chloride analysis of soil leachate using the TRAACS 800 analyser. Commun. Soil Sci. Plant Anal. 21(13-16):1689-1693.

Valcárcel, M. and M.D. Luque de Castro. 1987. Flow-Injection Analysis. Principles and Applications. Ellis Horwood Limited, Chichester, England.

Van Staden, J.F. 1987. Flow injection determination of inorganic bromide in soils with a coated tubular solid-state bromide-selective electrode. Analyst 112:595-599.

Xu, S. and Z. Fang. 1983. Simultaneous spectrophotometric determination of nitrate and nitrite in water and soil extracts by flow injection analysis. Fenxi Hauxue 11:93-97.

Xu, S., S. Zhang, and Z. Fang. 1989. Determination of ultra-trace amounts of selenium (IV) in water and soil extracts by flow injection on-line ion-exchange preconcentration hydride generation atomic absorption spectrometry. Chinese Sci. Bull. 35:526-527.

Wang, X. and Z. Fang. 1986. Determination of trace amounts of selenium in environmental samples by hydride generation. Atomic absorption spectrometry combined with flow injection analysis technique. Kexue Tongbao 31(11):791-792.

Wang, Z. and Y. Wang. 1992. Determination of arsenic, antimony and bismuth by flow injection analysis hydride-generation graphite-furnace atomic absorption spectrometry. Fenxi Huaxue 20 (6):670-673.

Willis, R.B. and C.E. Gentry. 1987. Automated method for determining nitrate and nitrite in water and soil extracts. Commun. Soil Sci. Plant Anal. 18(6):625-636. 
Zagatto, E.A.G., H. Bergamin Fo, S.M.B. Brienza, M.A.Z. Arruda, A.R.A. Nogueira, and J.L.F.C. Lima. 1992. Multi-site detection in flow analysis. Part 1. Relocation of spectrophotometric detector. Anal. Chim. Acta 261:59-65.

Zhang, S., L. Sun, H. Jiang, and Z. Fang. 1984. Determination of copper, zine, iron, manganese, sodium, potassium, calcium and magnesium in plants and soil by flow injection analysis. Guangpruxe Yu Guangpu Fenxi 4:42-47.

Zhang, S., Z. Fang, and J. Sun. 1987. Cold-vapor atomic absorption determination of mercury in soil and plants using a flow injection gas diffusion system. Guangpuxue Yu Guangpu Fenxi 7(1):57-61.

Zhi, Z., A. Ríos, and M. Valcárcel. 1994. Determination of soluble sulphate in soils by use of a filtration probe coupled with a flow injection system. Quim. Anal. 13:121-125. 